\title{
A Gestão e o Planejamento Integrado DOS RECURSOS HÍDRICOS: OCASO DA BARRAGEM DE CRISTALÂNDIA, NA BAHIA
}

\author{
José Carrera-Fernandez \\ Professor de Economia da Universidade \\ Federal da Babia e PhD* em Economia \\ pela The University of Chicago.
}

\section{RESUMO}

Este artigo aborda a questão do planejamento e gestão dos recursos hídricos, tema da maior relevância para o desenvolvimento econômico sustentável. Apresenta-se uma análise econômica criteriosa que busca delinear a melhor utilização conjunta dos recursos hídricos em uma perspectiva regional integrada, que leve em consideração não apenas os objetivos individuais de cada setor, mas principalmente os objetivos mais amplos de toda a sociedade, assim como esteja em consonância com o importante princípio dos usos múltiplos dos recursos hídricos. A barragem de Cristalândia, na bacia do rio de Contas, no Sudoeste do estado da Bahia, foi tomada para objeto deste estudo pela sua importância estratégica para o desenvolvimento dessa região. Os recursos hídricos disponibilizados pela referida barragem, além de cumprir com a sua função nobre no atendimento da demanda ecológica, foram eficientemente alocados para o abastecimento urbano de Brumado - importante município da região - e para o abastecimento rural e animal na área de influência do projeto, bem como para suprir as necessidades dos outros setores estratégicos e grandes usuários dos recursos da água que são a agricultura irrigada e a geração de energia elétrica. Ao har monizar e otimizar os interesses dos diversos setores usuários da água nessa região e buscar uma gestão intersetorial simétrica e autosustentável dos recursos hídricos aí disponibilizados, o projeto multifuncional de Cristalândia cumpre o seu papel na medida que lega a base de recursos hídricos necessária para as futuras gerações.

PALAVRAS CHAVE: Água, recursos hídricos, abastecimento público, irrigação, geração de energia elétrica

\section{ABSTRACT}

This paper approaches the issue of water resources management and planning, subject of great relevance to the sustainable economic development. A detailed analysis is presented as a means to delineate the best multiple utilization of water resources, from an integrated regional point of view, taking into consideration the larger goals of the society as a whole, and in consonance with the principle of multiple uses of water resources. The Cristalandia dam at the Contas river basin, in the Southwest region of the State of Babia, Brazil, was the focus of this study for its strategic importance to the development of that region. Besides accomplishing their noble function of meeting the ecological demands, the water resources disposed by this dam are efficiently allocated to satisfy the public supply system of Brumado, an important town in this region, and also of small rural and animal water supply systems in the area affected by the project, as well as to satisfy the needs of other strategical sectors and users, such as irrigation and electrical power generation. Since it harmonizes the concern of all water user sectors in that region and contributes to the improvement of the management efficiency of water resources disposed by that dam, the multifunctional project of Cristalandia accomplishes an important role, given that it bequeaths future generations the necessary water resources.

KEY WORDS: Water, public supply of water, irrigation, electrical energy generation 


\section{INTRODUÇÃO}

A busca de uma maior integração no planejamento e melhoria do gerenciamento dos recursos hídricos se constitui hoje, no país, tema da maior importância para o desenvolvimento regional sustentável. A principal dificuldade para implementar projetos integrados de utilização conjunta dos recursos hídricos se deve ao fato de não existir o mercado de água bruta, onde os direitos de propriedade, ou pelo menos os direitos de uso da água bruta, possam ser transacionados e os preços definidos. Em alguns casos, a avaliação dos benefícios e dos custos desses projetos exige do analista econômico um grande esforço para simular a situação de um mercado hipotético. Além disso, outras características específicas da água, que conferem a esse recurso a condição de bem público, contribuem ainda mais para dificultar a tarefa de gestão e planejamento dos recursos hídricos. Nesse sentido, os instrumentos econômicos aplicados através do mecanismo de mercado, juntamente com as ferramentas de ação e controle, desempenham um papel importante para o planejamento e gerenciamento integrado dos recursos hídricos.

A construção de uma barragem de regularização que expande a oferta de água para múltiplos setores usuários é um exemplo característico de bem público que, a depender do ponto de vista da análise, pode apresentar diferentes conclusões. Isso porque quando o investimento é efetivamente realizado, e independentemente se este é feito pela iniciativa privada ou pela administração pública, todos os usuários da água passam a se beneficiar automaticamente. Quando o investimento é analisado sob o ponto de vista privado, a construção dessa barragem tende a se tornar inviável, principalmente pelas dificuldades encontradas em mobilizar todos os beneficiários no sentido de que estes arquem com seus custos. Por outro lado, quando o projeto é avaliado sob o ponto de vista mais amplo da sociedade, a mensuração apropriada dos benefícios sociais gerados pela construção desse barramento faz com que estes excedam os seus custos, de modo que o projeto tende a ser economicamente viável ${ }^{1}$.

Este artigo se insere no contexto dos instrumentos econômicos que buscam a melhor utilização conjunta dos recursos hídricos, em uma perspectiva regional integrada, e visam harmonizar os interesses dos diversos setores usuários da água envolvidos em projetos multifuncionais. A melhor alocação dos recursos da água disponíveis em um sistema hídrico é equacionada através de um problema de otimização no qual os objetivos mais amplos da sociedade são levados em consideração, sem priorizar os objetivos específicos de algum grupo em particular. O modelo utilizado neste estudo segue as diretrizes daqueles apresentados em Rosegrant, Ringler, McKinney, Cai, Keller e Donoso (2000) e Carrera-Fernandez e Ferreira (2002), mas amplia o escopo da análise para incluir importantes questões que ainda não foram devidamente analisadas. A modelagem utilizada ao longo deste artigo está alicerçada no importante princípio dos usos múltiplos dos recursos hídricos, segundo o qual tais recursos devem situarse equiidistantemente acessível a todos usuários interessados em sua utilização, mas o predomínio desses recursos só deve ser dado àquele que, comprovadamente, gerar os maiores benefícios líquidos para a sociedade.

O projeto de construção da barragem multifuncional de Cristalândia foi tomado para objeto de estudo pela sua importância para o desenvolvimento integrado do Sudoeste do estado da Bahia. Os recursos hídricos disponibilizados pela referida barragem visam atender múltiplos setores usuários, tais como o abastecimento humano e animal, a agricultura irrigada e a geração hidrelétrica, além de satisfazer à demanda ecológica na preservação da vida aquática do próprio sistema hídrico. No que concerne ao abastecimento humano, o sistema atenderá as demandas por água potável da zona urbana do município de Brumado e das áreas rurais no seu entorno, assim como suprirá as necessidades das populações rurais distribuídas ao longo da adutora e dispersas em pequenas localidades e povoados na área de influência do projeto. A construção da barragem de Cristalândia beneficiará também o abastecimento animal, tanto na área de influência do projeto quanto ao longo da faixa da adutora até Brumado, além do que contribuirá para o setor agrícola da região, satisfazendo as demandas reprimidas bem como expandindo a área irrigada dessa região. Finalmente, os recursos hídricos aí acumulados permitirão também ampliar a geração de energia hidrelétrica, reduzindo a forte dependência do projeto em relação ao deficiente fornecimento de energia elétrica pela concessionária estadual ${ }^{2}$.

Além dessa introdução, este trabalho contém mais oito seções e está organizado da seguinte forma. Na segunda abordam-se a importância da gestão e do planejamento integrado dos recursos hídricos com a participação efetiva de to-

\footnotetext{
1 O que diferencia a análise social de projetos da avaliação sob o ponto de vista privado é que os benefícios e/ou os custos contabilizados por um grupo específico de agentes econômicos podem não ser os mesmos do que seriam para a sociedade como um todo. Isso porque, na presença de uma série de distorções econômicas e imperfeições de mercado, os benefícios e custos avaliados pela iniciativa privada tendem a diferir daqueles contabilizados pela sociedade. Além do que, a avaliação social de projetos está, necessariamente, relacionada com os objetivos maiores da sociedade, não estando restrita apenas aos interesses de um grupo específico desta.

2 Ressalte-se que a energia elétrica gerada no barramento atenderá integralmente as demandas de energia do projeto durante os dez primeiros anos da primeira etapa. Após esse período, o projeto prevê a construção de uma linha de transmissão e subestação para o atendimento das demandas por energia das duas etapas, como complementação de energia a partir da rede elétrica.
} 
dos os setores usuários. Na seção seguinte analisa-se, sob o ponto de vista regional, a necessidade da construção da barragem de Cristalândia para utilização conjunta dos recursos hídricos, visando garantir o desenvolvimento integrado e sustentável dessa região. Justifica-se aí a necessidade de uma avaliação criteriosa do projeto que, ao considerar os objetivos mais amplos da sociedade, funcione como um instrumento importante de planejamento e gestão dos recursos hídricos. Objetivando subsidiar as políticas de gestão dos recursos da água, na quarta seção desenvolve-se uma análise de otimização desses recursos, a partir das alternativas de utilização que se apresentam para a região. Nessa análise, os recursos hídricos disponibilizados em Cristalândia são equiidistantemente alocados aos setores usuários, de acordo com as necessidades preeminentes de cada um desses setores, buscando determinar a melhor repartição desses recursos para a sociedade.

Com base nessa alocação eficiente dos recursos da água, avaliam-se na quinta seção os custos sociais do projeto integrado de utilização múltipla dos recursos hídricos disponibilizados pela barragem de Cristalândia, a partir dos custos a preços de mercado. A seção seguinte trata da questão da cobrança pelo uso da água, importante instrumento de gestão dos recursos hídricos previsto na legislação que regula a matéria. Nessa seção faz-se uma revisão sucinta das várias metodologias de cobrança, objetivando subsidiar a escolha da metodologia mais apropriada para determinação dos preços pelo uso da água disponibilizada pela construção da referida barragem. Na sétima seção quantificam-se os benefícios diretos e indiretos do projeto multifuncional de Cristalândia. $\mathrm{Na}$ seção seguinte faz-se uma avaliação social desse projeto, confrontando os benefícios gerados pelo projeto com os custos sociais incorridos pelo mesmo. A última seção contém as conclusões e considerações finais deste trabalho, esperando que o mesmo possa contribuir para subsidiar as políticas públicas na área de recursos da água no país, melhorando assim a alocação desses recursos na economia.

\section{A GESTÃO E O PLANEJAMENTO DOS RECURSOS HIIDRICOS}

Em uma economia caracteristicamente marcada por uma série de imperfeições de mercado, a ação do estado é de fundamental importância para melhor a alocação de recursos escassos na economia. A intervenção do poder público é geralmente justificada nos casos onde as demandas reveladas e a oferta não são capazes de contabilizar os verdadeiros custos e benefícios sociais ou contabilizam apenas parte desses custos e benefícios. Este é o caso específico dos recursos da água em sistemas hídricos, os quais se apresentam com fortes características de bem público, além de serem suscetíveis a efeitos externos tecnológicos no consumo e na produção. Nesse caso, a ação pública, através das instituições e órgãos gestores dos recursos hídricos, pode ser necessária tanto para assegurar o nível socialmente ótimo de produção e consumo, quanto para corrigir distorções não desejáveis na alocação desses recursos, com ganhos para toda a sociedade.

A ação governamental é justificada sempre que houver a possibilidade de uma alocação mais apropriada dos recursos da água entre os seus múltiplos usuários, antevendo a possibilidade de conflitos pelo uso da água e garantindo os direitos individuais de cada usuário. No entanto, para que esses objetivos sejam, de fato, alcançados é necessário implementar certas ações, através de projetos, estabelecer princípios e criar instrumentos, que permitam assegurar uma disponibilidade hídrica a todos os seus usuários em um contexto de desenvolvimento econômico regional integrado.

As principais etapas no planejamento de projetos na área de recursos hídricos são: (i) estabelecimento de cenários de desenvolvimentos para a região e utilização dos recursos hídricos; (ii) quantificação das disponibilidades hídricas propiciadas pelo projeto de investimento; (iii) quantificação das demandas específicas de recursos hídricos em cada cenário de utilização desses recursos; (iv) confronto das disponibilidades hídricas com os cenários de utilização dos recursos hídricos; (v) elaboração dos projetos preliminares e estimativas dos custos; (vi) hierarquização dos projetos alternativos; (vii) análise da viabilidade social do projeto final; e (vii) estabelecimento de um gerenciamento que seja autosustentável financeiramente.

A análise social de projetos é um instrumento essencial para o planejamento dos recursos hídricos, principalmente porque ela permite que as entidades e os órgãos que compõem o setor possam reconhecer e escolher, entre vários projetos alternativos, o melhor para a sociedade, contribuindo assim para melhorar a alocação dos recursos escassos na economia. Além do mais, dado que os recursos públicos a serem investidos são escassos e insuficientes para implementar todos os projetos viáveis, a avaliação social de projetos permite que a sociedade possa ordenar os vários projetos disponíveis e escolher aqueles que deverão ser implementados primeiramente dentre um conjunto grande de possibilidades. Nesse sentido, a avaliação social de projetos permite uma hierarquização dos investimentos, de forma a compatibilizar a capacidade de investimento da sociedade com as suas necessidades.

$\mathrm{Na}$ gestão dos recursos hídricos, costuma-se levar em conta, primordialmente, o aspecto quantitativo relacionado ao uso da água. As vazões de retirada ou de reserva de água para uso não consuntivo e seus reflexos sobre o balanço hídrico dos diversos corpos d'água costumam ser o objeto dos maiores cuidados do administrador público. No entanto, não se pode dissociar o aspecto quantitativo do aspecto qualitativo, tendo em vista, sobretudo, o fato de que as águas, quando contaminadas, não podem ser consideradas como 
parte das disponibilidades para a maioria dos usos. Sendo assim, a gestão dos recursos hídricos implica, necessariamente, alguns cuidados e ações que estão abrigados, institucionalmente, no campo do gerenciamento ambiental.

Desafortunadamente, o setor público brasileiro está organizado de sorte tal que a gestão dos recursos hídricos está prevista em dois corpos institucionais distintos, ou seja, a entidade ou órgão gestor propriamente dito e a entidade ou órgão de gestão ambiental. Mas é forçoso reconhecer que a fronteira entre a gestão da qualidade e a gestão da quantidade da água não é muito nítida, fazendo com que os profissionais dedicados ao campo dos recursos hídricos estejam em permanente conexão com aqueles da área ambiental ${ }^{3}$. O fato de a legislação brasileira considerar a água como um bem público, não susceptível ao direito de propriedade, implica em incluir os recursos hídricos no universo de interesse da gestão ambiental, não ficando restritos apenas às leis de mercado. Nesse sentido, os instrumentos de ação e controle do estado desempenham um papel importante na gestão e no planejamento integrado dos recursos hídricos.

É importante ressaltar que os princípios de descentralização, participação e integração constituem a base e a espinha dorsal da gestão e do planejamento dos recursos hídricos e apontam para uma nova e moderna forma de administração desses recursos naturais e do próprio estado. Com a promulgação da Lei n- 9.433 no ano de 1997, iniciase uma nova política brasileira para os recursos hídricos, onde todos os agentes envolvidos na atividade de gerenciamento desses recursos começaram a gozar da necessária legitimidade para prosseguir em seus respectivos cursos de ação. Entre as diversas características dessa nova lei, existe uma de essencial importância que é a singularidade em sintetizar os princípios fundamentais do setor, criando os instrumentos de gestão do uso dos recursos hídricos e estabelecendo um arranjo institucional objetivando garantir o igual direito de uso a todos os usuários dos recursos hídricos.

Entre os princípios balizadores do novo arranjo setorial dos recursos hídricos no Brasil destacam-se: (i) a adoção da bacia hidrográfica como unidade físico-territorial de planejamento; (ii) o princípio dos usos múltiplos da água, na qual os recursos hídricos devem estar disponíveis em igualdade de oportunidades, para todos os usuários interessados em seu uso, dando prioridade em cada bacia ao uso que gerar os maiores benefícios sociais líquidos; (iii) o reconhecimento da água como um bem econômico, devido a sua escassez na natureza; e (iv) a gestão descentralizada, participativa e integra- da do uso da água. Todos esses princípios estão contidos na nova política nacional para o setor de recursos hídricos.

Em consonância com esses princípios foram criados instrumentos para o gerenciamento e planejamento dos recursos hídricos. Entre esses instrumentos, destacam-se: (i) os planos de recursos hídricos, que são planos diretores visando fundamentar e orientar a implementação da Política Nacional de Recursos Hídricos e o gerenciamento desses recursos; (ii) o enquadramento dos corpos de água em classes de usos preponderantes, que tem como objetivo assegurar às águas qualidade de acordo com os usos mais exigentes a que forem destinadas e diminuir os custos de combate à poluição através de medidas preventivas permanentes; (iii) a outorga de direitos de usos da água, que visa garantir o controle quantitativo e qualitativo dos usos da água e o efetivo direito de acesso de esse recurso a todos os seus usuários; (iv) o sistema de informações em recursos hídricos, mecanismo que disponibiliza dados, informações e índices de interesse para os recursos hídricos, servindo como instrumento para a tomada de decisão em planos e ações no setor; e (v) e a cobrança pelo uso dos recursos hídricos, que permite reconhecer a água como um bem econômico, incentivar a sua racionalização do uso e obter recursos financeiros para o financiamento de programas de ações, obras e intervenções contempladas nos planos de recursos hídricos.

A cobrança pelo uso da água e a outorga de direito de uso da água são dois instrumentos de gestão mais apropriados e eficazes para induzir o uso racional dos recursos hídricos e combater o uso perdulário da água. Especificamente, a cobrança pelo uso da água é uma das armas do "arsenal" econômico, que vem reforçar uma série de outros instrumentos de ação e controle utilizados pela administração pública, cujo objetivo principal é alocar eficientemente os recursos hídricos entre seus múltiplos usuários, além de racionalizar o uso desses recursos. De acordo com o Direito das Águas, a cobrança pelo uso dos recursos hídricos reflete o pagamento de um bem econômico e corresponde à retribuição pelo uso de um bem público.

Pode-se afirmar que o conjunto desses princípios e instrumentos é capaz de exercer uma grande influência em quase todo o universo de gerenciamento e planejamento dos usos da água. Mas, isso exigirá das instituições envolvidas um trabalho coordenado, sinérgico e encadeado, com a participação dos múltiplos atores e usuários da água no país. Além disso, e objetivando a implementação desses instrumentos, um novo arranjo institucional para o setor de recur-

3 São poucos os estados brasileiros que estruturaram a gestão dos recursos hídricos no corpo da hierarquia da gestão ambiental. É o caso, por exemplo, de Mato Grosso, onde a Fundação Estadual do Meio Ambiente - FEMA também se ocupa da gestão dos recursos hídricos. A maioria dos estados atua por meio de instituições distintas, uma para a gestão ambiental e outra para a gestão do uso dos mananciais. A própria União atua através do Instituto Brasileiro do Meio Ambiente - IBAMA e da Agência Nacional de Águas - ANA, para questões ambientais e de água, respectivamente. 
sos hídricos foi concebido com a criação da Agência Nacional de Águas - ANA e de instituições como o Conselho Nacional de Recursos Hídricos (instância composta por representantes dos ministérios e secretarias da Presidência da República, além de abrigar representantes dos conselhos estaduais de recursos hídricos e de representantes das organizações civis de recursos hídricos), os comitês de bacia hidrográfica (fóruns de discussão e de decisão sobre projetos, programas e intervenções a serem implementadas na bacia hidrográfica) e as agências de água.

Dentro dessa nova concepção institucional para o setor de recursos hídricos, apresenta-se a possibilidade de construção de barragens para múltipla utilização desses recursos em uma perspectiva de desenvolvimento regional integrado. Analisa-se, a seguir, o projeto específico de construção da barragem de Cristalândia, na bacia hidrográfica do rio de Contas, na Bahia, observando-se os aspectos relativos ao desenvolvimento regional induzido pela utilização conjunta e integrada dos recursos hídricos aí disponibilizados.

\section{O PROJETO DE CONSTRUÇÃODABARRAGEM DE CRISTALÂNDIA E A UTILIZAÇÃO CONJUN- TA DOS RECURSOS HÍDRICOS}

A região de influência do projeto de construção da barragem de Cristalândia faz parte da bacia hidrográfica do Rio de Contas e está localizada no Sudoeste do estado da Bahia. Os municípios que compõem essa região são Brumado, Ituaçu e Rio de Contas, os quais estão totalmente inseridos no polígono das secas. Essa região é polarizada pelo município de Brumado que, aproveitando a sua localização estratégica como entroncamento rodoviário, funciona como um pólo de atração de negócios da região, principalmente no setor de comércio e serviços.

A indisponibilidade de água potável para atender os sistemas de abastecimento da região é um problema que vem se agravando nos últimos anos, principalmente para atender o município de Brumado. O sistema de abastecimento de Brumado, que é operado pela Empresa Baiana de Saneamento - EMBASA e faz suas captações no rio do Antônio, está atualmente enfrentando problemas com a qualidade de suas águas, resultante da decomposição orgânica de grande quantidade de algas tóxicas nos reservatórios de captação. Esse é um problema que poderá ser solucionado com a construção da adutora prevista pelo projeto de Cristalândia, garantindo assim o desenvolvimento econômico do município. Deve-se também ressaltar que a região dispõe de uma grande quantidade de terras férteis e uma enorme vocação agrícola, mas esbarra na indisponibilidade de água para desenvolver a sua agricultura irrigada. Além do mais, a geração de energia elétrica é fun-

Fonte: $\mathrm{O}$ autor damental para a região, tendo em vista que o seu sistema elétrico, que é operado pela Companhia de Energia Elétrica da Bahia - COELBA e tem como fonte geradora a usina hidrelétrica de Paulo Afonso da Companhia Hidro Elétrica do São Francisco - CHESF, não tem condições de atender as crescentes demandas.

A definição da altura da barragem de Cristalândia e a correspondente vazão de regularização a ser disponibilizada pela mesma foram objetos de estudo prévio de viabilidade, tomando-se como referência três cenários distintos de aproveitamento dos recursos hídricos aí disponibilizados. No primeiro, visou-se atender apenas a principal prioridade da região, que é o abastecimento público urbano e rural. Em um segundo cenário, contemplou-se a possibilidade do aproveitamento desses recursos para a agricultura irrigada, além é claro da utilização dos recursos hídricos para a finalidade prioritária de abastecimento público. Finalmente, no terceiro cenário vislumbrou-se a utilização conjunta entre todos os setores usuários, o que significava incluir também a possibilidade de geração de energia elétrica. A tabela 3.1 resume as principais características em cada um desses cenários de aproveitamento dos recursos hídricos. Os estudos preliminares comprovaram que o terceiro cenário de utilização conjunta dos recursos hídricos era aquele que comandava os melhores indicadores de viabilidade econômica, além do que minimizava os custos com concreto. A grande questão é como repartir entre os múltiplos usuários os recursos hídricos disponibilizados pela barragem de Cristalândia de modo a maximizar os benefícios sociais líquidos e garantir a sustentabilidade do sistema hídrico para as futuras gerações.

TABELA 3.1: Cenários de aproveitamento dos recursos

\begin{tabular}{lccc}
\hline \multirow{2}{*}{ Cenários de utilização dos recursos hídricos } & $\begin{array}{c}\text { Demanda por água } \\
\text { em final de projeto }\end{array}$ & $\begin{array}{c}\text { Vazão regularizada } \\
\text { com 100\% de garantia }\end{array}$ & $\begin{array}{c}\text { Custo com } \\
\text { concreto }\end{array}$ \\
\cline { 2 - 5 } & $\mathbf{( 1 / \mathbf { s } )}$ & $\mathbf{( / / \mathbf { s } )}$ & $\mathbf{( R S )}$ \\
\hline Prioridade ao abastecimento público & 240,1 & 1.400 & 23.876 .804 \\
Atendimento ao abastecimento público e a irrigação & $6.665,7$ & 3.100 & 40.866 .818 \\
Abastecimento, irrigação e geração de energia elétrica & $8.910,7$ & 3.300 & 40.866 .818 \\
\hline
\end{tabular}

Ao vislumbrar uma utilização conjunta dos recursos hídricos, o projeto de construção da barragem de Cristalândia é uma opção real que visa resolver os problemas dessa importante região e contribui para o seu desenvolvimento integrado e sustentável. Pois, além de suprir as necessidades atuais e futuras do sistema de abastecimento de água da zona urbana de Brumado e as áreas rurais no seu entorno, os recursos hídricos acumulados pela barragem visam atender as necessidades de água da população rural dispersa, distribuída ao longo da adutora e em pequenas localidades e povoados na área de influência da barragem. De fato, o projeto de Cristalândia beneficiará uma população de 51 mil habitantes, sendo que 40 mil estão concentrados na zona ur- 
bana de Brumado, enquanto que cerca de 11 mil vivem em pequenos lugarejos próximos à cidade e fora dos limites $\mathrm{da}$ área urbana. Além do mais, o projeto também beneficiará 58 vilas e povoados dispersos nos três municípios, atendendo 1.067 domicílios e uma população de 4.268 habitantes ${ }^{4}$.

Os recursos hídricos disponibilizados em Cristalândia visam também suprir outras finalidades de uso, tais como a demanda ecológica, na preservação da vida aquática do próprio sistema hídrico; o abastecimento animal, tanto na área de influência do projeto quanto ao longo da faixa adutora até Brumado; a irrigação, satisfazendo as demandas reprimidas bem como possibilitando expandir a área irrigada dessa região; e a geração de energia elétrica, através da construção de uma pequena central hidrelétrica - $\mathrm{PCH}$ no próprio barramento.

A demanda por água para dessedentação de animais, a qual será agregada à demanda por água para abastecimento rural, foi avaliada em função dos rebanhos de grande porte (bovinos, eqüinos, asininos e muares) e os de pequeno porte (suínos, ovinos e caprinos) existentes na área de influência do barramento, adotando-se uma taxa anual de crescimento de 0,2\% para ambos os tipos de rebanhos 5 . O consumo per capita animal utilizado foi o usual em projetos dessa natureza.

No que concerne às demandas por

TABELA 3.2: Demandas por água nas várias modalidades de uso (em $1 / \mathrm{s})$

\begin{tabular}{lrrrrrr}
\hline Modalidade de uso & VP da água $\mathbf{~ ( 1 0 0 0 ~}^{\mathbf{3}}$ ) & \multicolumn{1}{c}{$\mathbf{2 0 0 2}$} & $\mathbf{2 0 0 7}$ & $\mathbf{2 0 1 2}$ & $\mathbf{2 0 2 2}$ & \multicolumn{1}{c}{$\mathbf{2 0 3 2}$} \\
\hline Abastecimento urbano & 37.986 & 127,7 & 141,3 & 156,4 & 191,5 & 234,5 \\
Abastecimento rural & 1.315 & 5,1 & 5,2 & 5,2 & 5,4 & 5,6 \\
Irrigação & 595.311 & 127,6 & $1.702,1$ & $3.276,6$ & $6.425,6$ & $6.425,6$ \\
Geração de energia elétrica & 491.554 & $1.746,4$ & $1.929,7$ & $2.132,2$ & $1.837,7$ & $2.245,0$ \\
Total & $\mathbf{1 . 1 2 6 . 1 6 6}$ & $\mathbf{2 . 0 0 6 , 8}$ & $\mathbf{3 . 7 7 8 , 3}$ & $\mathbf{5 . 5 7 0 , 4}$ & $\mathbf{8 . 4 6 0 , 2}$ & $\mathbf{8 . 9 1 0 , 7}$ \\
\hline
\end{tabular}

Fonte: $\mathrm{O}$ autor água para irrigação, a necessidade atual para os 50 irrigantes cadastrados é de $391 / \mathrm{s}$, enquanto que a demanda reprimida situa-se em torno de $89 \mathrm{l} / \mathrm{s}$, atendendo uma área irrigada de 313 hectares. Além do mais, estima-se que a área irrigada na região de influência da barragem poderá ser expandida em 10.700 ha, a uma taxa de 5\% ao ano, até atingir, em 20 anos, a demanda máxima prevista para essa modalidade de uso, que é de $6.4261 / \mathrm{s}$. Os estudos pedológicos já realizados dão conta que a área potencialmente ir rigável é bem maior que a área prevista pelo projeto para essa finalidade de uso.

$O$ fato de a barragem de Cristalândia gerar a energia elétrica necessária para atender as novas demandas da região configura-se, portanto, como elemento positivo para viabilizar o desenvolvimento do projeto integrado de utilização dos recursos hídricos da região ${ }^{6}$. A energia aí produzida servirá principalmente para suprir as estações elevatórias e de tratamento dos sistemas de abastecimento da água potável e as estações de bombeamento para os vários sistemas simplificados de irrigação. Além de reduzir a dependência do projeto em relação ao fornecimento de eletricidade pela concessionária estadual, essa geração de energia também permitirá expandir o baixo consumo de energia elétrica rural verificada nessa região.

A tabela 3.2 dispõe a projeção das demandas por água bruta nas várias modalidades de uso, para alguns anos selecionados ao longo do horizonte do projeto, avaliadas de acordo com as necessidades e os requerimentos técnicos de cada setor usuário. A segunda coluna desse quadro mostra também o valor presente da água disponibilizada nas várias modalidades de uso da água disponibilizada pela barragem de Cristalândia, o qual foi avaliado com base na taxa social de desconto de $15 \%$ ao ano. 


\section{O MODELO DE OTIMIZAÇÃO DOS RECURSOS HÍDRICOS}

A gestão dos recursos hídricos é uma atividade econômica que traz consigo um custo marginal baixíssimo ou muito próximo de zero. Isso porque a água é um recurso natural renovável, de modo que o aumento na sua utilização, tanto no seu componente quantitativo quanto qualitativo, não está diretamente associado a um aumento no custo de oferta. No entanto, o gerenciamento dos recursos da água exige certos custos fixos, resultantes de investimentos em projetos, obras e ações necessárias para garantir a oferta desse recurso, além, é claro, dos custos de operação e manutenção do próprio sistema hídrico. Isso significa que os usuários terão que, de alguma forma, arcar com esses custos, sob pena de a oferta desse recurso ser reduzida, restringindo conseqüentemente a sua utilização, com prejuízos para toda a sociedade.

Uma das atribuições do setor de recursos hídricos é implementar a cobrança pelo uso dos recursos hídricos, orientando inclusive a escolha da melhor metodologia para determinação dos preços. Ressalte-se que a cobrança pelo uso da água é plenamente justificável como mecanismo de financiamento dos investimentos e custos imprescindíveis à atividade de gestão dos recursos hídricos. A metodologia utilizada para avaliar os preços pelo uso dos recursos hídricos na barragem de Cristalândia foi a de custo marginal (social) de longo prazo, questão que será retomada na sexta seção.

Conforme mencionado anteriormente, o modelo apresentado a seguir busca definir a melhor repartição dos recursos hídricos entre os três maiores setores usuários, que são o abastecimento público, a agricultura irrigada e a geração de energia elétrica, os quais interagem competindo pelo uso desses recursos. Deve-se ressaltar que a melhor alocação da água é aquela que maximiza o bem-estar social, contribuindo assim para guiar a economia na direção da fronteira Pareto ótima, com ganhos líquidos para toda a sociedade e não apenas para algum setor específico.

\section{1. $\mathrm{O}$ abastecimento de água}

É importante ressaltar que, de acordo com a legislação brasileira vigente, o abastecimento público de água potável tem prioridade de uso sobre qualquer outro setor usuário dos recursos hídricos. Por simplicidade supõe-se que a companhia de abastecimento público produz água potável com uma tecnologia linear, especificada da seguinte forma:

$$
\mathrm{y}_{\mathrm{a}}=\gamma_{\mathrm{a}} \mathrm{x}_{\mathrm{a}}=\gamma_{\mathrm{a}}\left(\mathrm{x}_{\mathrm{au}}+\mathrm{x}_{\mathrm{ar}}\right)
$$

onde y é o nível de produção de água potável da companhia, $x_{a}$ é a quantidade de água bruta que a empresa capta do manancial, $\mathrm{x}_{\mathrm{au}}$ e $\mathrm{x}_{\mathrm{ar}}$ são as quantidades de água no abastecimento urbano e rural, respectivamente, e $g_{a}$ é o coeficiente técnico (parâmetro de eficiência) da empresa, que transforma água bruta em água potável ${ }^{1}$. Supõe-se que a companhia de abastecimento atua em um mercado monopolístico, enfrentando uma função de demanda linear, a qual é especificada por:

$$
\mathrm{y}_{\mathrm{a}}=\alpha_{\mathrm{a}}-\mathrm{P}_{\mathrm{a}}(4.1 .2)
$$

sendo que $\mathrm{P}_{\mathrm{a}}$ é o preço da água potável praticado pela companhia e a é o consumo autônomo de água tratada dessa empresa, ou seja, é a máxima quantidade que os usuários estariam dispostos a consumir ao preço zero.

Admite-se que a função de lucro do setor de abastecimento público é estabelecida da seguinte forma:

$$
\pi_{\mathrm{a}}=\mathrm{P}_{\mathrm{a}} \mathrm{y}_{\mathrm{a}}-\mathrm{f}_{\mathrm{a}}-\mathrm{c}_{\mathrm{a}} \mathrm{y}_{\mathrm{a}}-\mathrm{p}_{\mathrm{au}}{ }^{*} \mathrm{x}_{\mathrm{au}}-\mathrm{p}_{\mathrm{ar}}{ }^{*} \mathrm{x}_{\mathrm{ar}}
$$

ou

$\pi_{\mathrm{a}}=\gamma_{\mathrm{a}}\left(\alpha_{\mathrm{a}}-\mathrm{c}_{\mathrm{a}}\right)\left(\mathrm{x}_{\mathrm{au}}+\mathrm{x}_{\mathrm{ar}}\right)-\mathrm{p}_{\mathrm{au}}{ }^{*} \mathrm{x}_{\mathrm{au}}-\mathrm{p}_{\mathrm{ar}}{ }^{*} \mathrm{x}_{\mathrm{ar}}-\gamma_{\mathrm{a}}{ }^{2}\left(\mathrm{x}_{\mathrm{au}}+\mathrm{x}_{\mathrm{ar}}\right)^{2}-\mathrm{f}_{\mathrm{a}}$

onde c é o custo marginal (privado) de produção de água potável da companhia, o qual não inclui o pagamento pelo uso da água, $\mathrm{f}_{\mathrm{a}}$ é o seu custo fixo e $\mathrm{p}_{\mathrm{au}}{ }^{*} \mathrm{e} \mathrm{p}_{\mathrm{ar}}{ }^{*}$ são os preços pelo uso da água no abastecimento urbano e rural, respectivamente, cujos valores foram: $\mathrm{p}_{\mathrm{au}}{ }^{*}=0,903 \mathrm{e} \mathrm{p}_{\mathrm{ar}}{ }^{*}=$ 0,884 , ambos em $\mathrm{R} \$ / \mathrm{m}^{3}$.

\subsection{A agricultura irrigada}

Admite-se que as firmas operando no setor agrícola de irrigação são competitivas e produzem de acordo com uma tecnologia linear, especificada da seguinte forma:

$$
\mathrm{y}_{\mathrm{i}}^{\mathrm{j}}=\gamma_{\mathrm{i}}^{\mathrm{j}} \mathrm{x}_{\mathrm{i}}^{\mathrm{j}} \quad \text { (4.2.1) }
$$

onde $y_{i}^{j}$ é o nível de produção da cultura j, $x_{i}^{j}$ é a quantidade de água bruta utilizada na irrigação dessa cultura e $\mathrm{g}_{\mathrm{i}}^{j}$ é o parâmetro de eficiência da cultura j, o qual depende do método de irrigação, do coeficiente de infiltração e do índice de evapotranspiração da região, entre outros.

Supõe-se que o custo marginal de produção do irrigante $\mathrm{j}$ cresce com a área irrigada (ou seja, com a utilização de água) de acordo com a seguinte expressão:

7 As perdas de água no abastecimento público no Brasil correspondem a 33\%, em média, mas em alguns casos podem até ultrapassar os $50 \%$. Isso significa que o parâmetro $\mathrm{g}_{\mathrm{a}}$ está em torno de 0,67 . 


$$
\mathrm{CMg}_{\mathrm{i}}=\mathrm{c}_{\mathrm{i}}^{\mathrm{j}}\left[1+\delta\left(\mathrm{x}_{\mathrm{i}}^{\mathrm{j}}-\mathrm{x}_{\mathrm{i}}{ }^{\prime}\right) / \mathrm{x}_{\mathrm{i}}{ }^{\prime}\right]
$$

sendo que $c_{i}$ é o custo marginal médio de produção da agricultura ir rigada ${ }^{1} ; \mathrm{d}>0$ é o fator de aumento no custo de irrigação em função da distância do manancial; e $\left(x_{i}-x_{i}{ }^{\prime}\right) /$ $\mathrm{x}_{\mathrm{i}}^{\prime}=\mathrm{x}_{\mathrm{i}} / \mathrm{x}_{\mathrm{i}}^{\prime}-1$ é o fator de correção do custo de irrig ação em relação ao nível x,', considerado de baixo custo de irrigação, em termos de distância de recalque.

Desde que as firmas operando nesse setor são competitivas e, portanto, tomam o preço do produto $\mathrm{P}_{\mathrm{i}}^{\mathrm{j}}$ como dado, então a função de lucro da atividade agrícola de irrigação é estabelecida da seguinte forma:

$$
\pi_{\mathrm{i}}=\Sigma_{\mathrm{j}}\left\{\mathrm{P}_{\mathrm{i}}^{\mathrm{j}} \mathrm{y}_{\mathrm{i}}^{\mathrm{j}}-\mathrm{f}_{\mathrm{i}}^{\mathrm{j}}-\mathrm{c}_{\mathrm{i}}^{\mathrm{j}}\left[1+\delta\left(\mathrm{x}_{\mathrm{i}}^{\mathrm{j}}-\mathrm{x}_{\mathrm{i}}^{\mathrm{j}}\right)\right] \mathrm{y}_{\mathrm{i}}^{\mathrm{j}}\right\}-\mathrm{p}_{\mathrm{i}}^{*} \Sigma_{\mathrm{j}} \mathrm{x}_{\mathrm{i}}^{\mathrm{j}}
$$

ou

$$
\pi_{\mathrm{i}}=\Sigma_{\mathrm{j}} \gamma_{\mathrm{i}}^{\mathrm{j}}\left\{\mathrm{P}_{\mathrm{i}}^{\mathrm{j}}-\mathrm{c}_{\mathrm{i}}^{\mathrm{j}}\left[1-\delta+\delta\left(\mathrm{x}_{\mathrm{i}}^{\mathrm{j}} / \mathrm{x}_{\mathrm{i}}^{\mathrm{j}},\right)\right]-\mathrm{p}_{\mathrm{i}}^{*}\right\} \mathrm{x}_{\mathrm{i}}^{\mathrm{j}}-\Sigma_{\mathrm{j}} \mathrm{f}_{\mathrm{i}}^{\mathrm{j}}
$$

onde $P_{i}^{\mathrm{j}}$ é o preço médio do produto agrícola de irrigação j; c c é o custo marginal (privado) de produção da firma típica $j$, que não inclui o pagamento pelo uso da água; $f_{i}^{j}$ é o seu custo fixo; $\mathrm{p}_{i}{ }^{*}$ é o preço pelo uso da água na agricultura irrigada; e x. 'e o nível de utilização de água para irrigação a baixo custo.

\subsection{A geração de energia elétrica}

No mercado de energia elétrica, a tarifa é administrada pela própria Agência Nacional de Energia Elétrica - ANEEL, em função dos custos das usinas e de parâmetros previamente estabelecidos. Nesse contexto, supõe-se que a usina geradora toma a tarifa de energia elétrica $\mathrm{P}_{\mathrm{e}}^{*}$ (ou o montante $\mathrm{da}$ "energia assegurada" $\mathrm{P}_{\mathrm{e}} \mathrm{y}_{\mathrm{e}}$ ) como dada e determina a quantidade de água utilizada para produção de energia elétrica, $\mathrm{x}_{\mathrm{e}}$, de acordo com a seguinte tecnologia linear ${ }^{9}$ :

$$
\mathrm{x}_{\mathrm{e}}=\mathrm{y}_{\mathrm{e}} / \gamma(4.3 .1)
$$

onde $y_{e}$ é a quantidade de energia elétrica a ser produzida pela geradora e $g_{e}$ é o parâmetro de eficiência da geradora, ou seja, o coeficiente que transforma água em energia elétrica.

A função de lucro da atividade de geração de energia elétrica pode ser estabelecida da seguinte forma:

$$
\pi_{\mathrm{e}}=\mathrm{P}_{\mathrm{e}}{ }^{*} \mathrm{y}_{\mathrm{e}}-\mathrm{f}_{\mathrm{e}}-\mathrm{c}_{\mathrm{e}} \mathrm{y}_{\mathrm{e}}-\mathrm{p}_{\mathrm{e}}{ }^{*} \mathrm{x}_{\mathrm{e}}=\left[\gamma_{\mathrm{e}}\left(\mathrm{P}_{\mathrm{e}}{ }^{*}-\mathrm{c}_{\mathrm{e}}\right)-\mathrm{p}_{\mathrm{e}}{ }^{*}\right] \mathrm{x}_{\mathrm{e}}-\mathrm{f}_{\mathrm{e}}
$$

onde $c_{e}$ é o custo marginal (privado) de produção de energia elétrica da geradora, o qual não inclui o pagamento pelo uso da água nessa finalidade, $\mathrm{f}_{\mathrm{e}}$ é o seu custo fixo e $\mathrm{p}_{\mathrm{e}}{ }^{*}$ é o preço pelo uso da água ${ }^{10}$.

\subsection{A SOLUÇÃO}

O principal objetivo da instituição gestora dos recursos hídricos é promover a repartição desses recursos entre esses três setores usuários, estabelecendo um padrão de uso eficiente que seja consoante com a perspectiva mais ampla da sociedade. Dessa forma, postula-se que o objetivo do gerenciamento é otimizar o benefício social líquido. Isto é, supõe-se que a instituição ou órgão gestor dos recursos da água otimiza uma função de excedente econômico agregado, a qual engloba os lucros conjuntos dos setores usuários, sem estabelecer, a priori, qualquer preferência sobre a utilização dos recursos hídricos, em conformidade com o importante princípio dos usos múltiplos.

É importante lembrar que a demanda por água para abastecimento $\mathrm{x}_{\mathrm{a}}^{*}=\mathrm{x}_{\mathrm{au}}{ }^{*}+\mathrm{x}_{\mathrm{ar}}{ }^{*}$ deverá ser garantida pelo sistema hídrico, tendo em vista que essa modalidade de uso tem prioridade sobre qualquer outra utilização que se dê a esse recurso. Isso significa que a vazão remanescente, a ser repartida entre os setores de geração de energia elétrica e ir rigação, deverá satisfazer a seguinte condição:

$$
\Sigma_{\mathrm{j}} \mathrm{x}_{\mathrm{i}}^{\mathrm{j}}+\mathrm{x}_{\mathrm{e}} \leq \mathrm{x}-\mathrm{x}_{\mathrm{a}}{ }^{*}
$$

sendo que x é a vazão disponibilizada pela barragem. Tomando a restrição de vazão (4.4.1), os preços pelo uso da água para irrigação $p_{i}^{*}$ e para geração de energia elétrica $\mathrm{P}_{\mathrm{i}}{ }^{*}$, o preço dos produtos agrícolas de irrigação $\mathrm{P}_{\mathrm{i}}^{\mathrm{j}}$ e a tarifa de energia elétrica $\mathrm{P}_{\mathrm{e}}^{*}$ como dados, então o objetivo é determinar os níveis ótimos de utilização de recursos hídricos para essas finalidades de uso de modo a maximizar os lucros conjuntos desses dois setores usuários, ou seja:

$$
\begin{aligned}
& \max \pi=\pi_{\mathrm{i}}+\pi_{\mathrm{e}}= \\
& \quad=\left\{\Sigma_{\mathrm{j}} \gamma_{\mathrm{i}}^{\mathrm{j}}\left[\mathrm{P}_{\mathrm{i}}^{\mathrm{j}}-\mathrm{c}_{\mathrm{i}}^{\mathrm{j}}\left(1-\delta+\delta\left(\mathrm{x}_{\mathrm{i}}^{\mathrm{j}} / \mathrm{x}_{\mathrm{i}}^{\mathrm{j}}\right)\right)\right]-\mathrm{p}_{\mathrm{i}}{ }^{*}\right\} \mathrm{x}_{\mathrm{i}}{ }^{\mathrm{j}}-\Sigma_{\mathrm{j}} \mathrm{f}_{\mathrm{i}}^{\mathrm{j}}+ \\
& +\left[\gamma_{\mathrm{e}}\left(\mathrm{P}_{\mathrm{e}}{ }^{*}-\mathrm{c}_{\mathrm{e}}\right)-\mathrm{p}_{\mathrm{e}}{ }^{*}\right] \mathrm{x}_{\mathrm{e}}-\mathrm{f}_{\mathrm{e}} \\
& \quad \mathrm{x}_{\mathrm{i}}{ }^{,} \mathrm{x}_{\mathrm{e}} \\
& \text { s.a. } \Sigma_{\mathrm{j}} \mathrm{x}_{\mathrm{i}}^{\mathrm{j}}+\mathrm{x}_{\mathrm{e}} \leq \mathrm{x}_{0} \\
& \quad \Sigma_{\mathrm{j}} \mathrm{x}_{\mathrm{i}}^{\mathrm{j}}, \mathrm{x}_{\mathrm{e}} \geq 0
\end{aligned}
$$

8 Avaliado em relação aos três mais importantes cultivares produzidos na área da bacia, ou seja, café, feijão e milho.

9 Ressalte-se que a atividade de geração é também administrada pelo Operador Nacional do Sistema (ONS), o qual escolhe a quantidade a ser produzida pelas centrais em função de um ótimo coletivo.

10 Vale lembrar que, de acordo com a nova legislação de águas, o setor elétrico terá que transferir ao setor de recursos hídricos, a título de cobrança pelo uso da água nessa finalidade de uso, a parcela corresponde a 0,75\% do valor da energia produzida. 
onde $\mathrm{x}_{0}=\mathrm{x}-\mathrm{x}_{\mathrm{a}}$ é a vazão remanescente do manancial a ser repartida. As condições de primeira ordem para um ótimo interior desse problema (teorema de Kuhn-Tucker) são ${ }^{11}$ :

$$
\begin{aligned}
& \partial \pi / \partial \mathrm{x}_{\mathrm{i}}^{\mathrm{j}}= \\
& \left.=\Sigma_{\mathrm{j}} \gamma_{\mathrm{i}}^{\mathrm{j}}\left\{\mathrm{P}_{\mathrm{i}}-\mathrm{c}_{\mathrm{i}}^{\mathrm{j}}\left[1-\delta+\delta\left(\mathrm{x}_{\mathrm{i}}^{\mathrm{j}} / \mathrm{x}_{\mathrm{i}}^{\mathrm{j},}\right)\right]\right\}-\mathrm{p}_{\mathrm{i}}{ }^{*}-\delta \Sigma_{\mathrm{j}} \gamma_{\mathrm{i}}^{\mathrm{j}} \mathrm{c}_{\mathrm{i}}^{\mathrm{j}}\left(\mathrm{x}_{\mathrm{i}}^{\mathrm{j}} / \mathrm{x}_{\mathrm{i}}^{\mathrm{j},}\right)\right\}-\lambda \leq 0, \\
& \text { ou }=0 \text { se } \mathrm{x}_{\mathrm{i}}^{\mathrm{j}}>0
\end{aligned}
$$

$$
\partial \pi / \partial \mathrm{x}_{\mathrm{e}}=\gamma_{\mathrm{e}}\left(\mathrm{P}_{\mathrm{e}}{ }^{*}-\mathrm{c}_{\mathrm{e}}\right)-\mathrm{p}_{\mathrm{e}}{ }^{*}-\lambda \leq 0,
$$$$
\text { ou }=0 \text { se } x_{\mathrm{e}}>0
$$

$\partial \pi / \partial \lambda=\mathrm{x}_{0}-\Sigma_{\mathrm{j}} \mathrm{x}_{\mathrm{i}}^{\mathrm{j}}-\mathrm{x}_{\mathrm{e}} \geq 0$ se $\lambda \geq 0$,

ou $=0$ se $\lambda>0$

sendoque $\lambda$ é o multiplicador de Lagrange, o qual pode ser interpretado como sendo o custo marginal de utilização da água bruta ao relaxar-se a restrição de vazão em mais um metro cúbico por segundo.

As duas primeiras condições têm uma implicação interessante, pois elas estabelecem que a alocação dos recursos hídricos entre esses dois setores usuários será otimizada, e o lucro conjunto maximizado, quando o nível de produção de cada setor usuário for estendido até o ponto em que os benefícios marginais líquidos desses setores forem iguais.

Admitindo-se uma solução interior (ou seja, $\Sigma x_{i}^{j}>0$ ex $\left.x_{e}>0\right)$ e combinando-se as duas primeiras condiçốes de primeira ordem, resulta:

$$
\begin{aligned}
& \mathrm{x}_{\mathrm{i}}^{*}=\mathrm{x}_{\mathrm{i}}{ }^{\prime}\left\{\Sigma_{\mathrm{j}} \gamma_{\mathrm{i}}^{\mathrm{j}}\left[\mathrm{P}_{\mathrm{i}}^{\mathrm{j}}-\mathrm{c}_{\mathrm{i}}^{\mathrm{j}}(1-\delta)\right]-\right. \\
& \left.-\mathrm{p}_{\mathrm{i}}^{*}-\gamma_{\mathrm{e}}\left(\mathrm{P}_{\mathrm{e}}{ }^{*}-\mathrm{c}_{\mathrm{e}}\right)+\mathrm{p}_{\mathrm{e}}^{*}\right\} / 2 \delta \Sigma_{\mathrm{j}} \gamma_{\mathrm{i}} \mathrm{c}_{\mathrm{i}}^{\mathrm{j}}
\end{aligned}
$$

Finalmente, substituindo-se (4.4.6) na primeira equação de restrição do problema de otimização (4.4.2), obtémse a vazão ótima para o setor de geração de energia elétrica:

$$
\begin{aligned}
& \mathrm{x}_{\mathrm{e}}{ }^{*}=\mathrm{x}_{0}-\mathrm{x}_{\mathrm{i}}{ }^{\prime}\left\{\Sigma_{\mathrm{j}} \gamma_{\mathrm{i}}^{\mathrm{j}}\left[\mathrm{P}_{\mathrm{i}}^{\mathrm{j}}-\mathrm{c}_{\mathrm{i}}^{\mathrm{j}}(1-\delta)\right]-\right. \\
& \left.-\mathrm{p}_{\mathrm{i}}{ }^{*}-\gamma_{\mathrm{e}}\left(\mathrm{P}_{\mathrm{e}}{ }^{*}-\mathrm{c}_{\mathrm{e}}\right)+\mathrm{p}_{\mathrm{e}}{ }^{*}\right\} / 2 \delta \Sigma_{\mathrm{j}} \gamma_{\mathrm{i}}{ }^{\mathrm{j}} \mathrm{c}_{\mathrm{i}}^{\mathrm{j}}
\end{aligned}
$$

Deve-se ressaltar que ao serem alocadas as vazões óti$\operatorname{mas}_{\mathrm{e}}{ }^{*}>0 \mathrm{ex} \mathrm{x}_{\mathrm{i}}^{*}>0$, as quais satisfazem a restrição de que $\mathrm{x}_{\mathrm{i}}^{*}+\mathrm{x}_{\mathrm{e}}^{*} \leq \mathrm{x}-\mathrm{x}_{\mathrm{a}}^{*}$, pode-se garantir que todos os setores usuários estarão realizando suas produções ótimas, de modo que $\mathrm{y}_{\mathrm{e}}{ }^{*}>0 \mathrm{e} \mathrm{y}_{\mathrm{i}}^{*}>0$. Em conseqüência, o lucro conjunto desses dois setores será, portanto, maximizado. Além disso, garante-se também a realização da produção ótima de água potável para o abastecimento público de Brumado ${ }_{a}^{*}>0$, a qual tem prioridade por força de lei.

A intuição por trás desse resultado é que, ao ser otimizado o benefício social líquido, cria-se um mecanismo que permite internalizar (aos custos privados de produção) todos os efeitos externos (negativos e positivos) causados por cada setor usuário aos outros usuários dos recursos hídricos. Isso permite uma melhoria na alocação dos recursos hídricos entre os seus múltiplos usuários, relativamente à solução em que cada setor busca otimizar os seus lucros individualmente, com ganhos para toda a sociedade.

A solução desse problema de otimização estabelece a alocação ótima dos recursos hídricos na referida bacia entre os setores usuários. De fato, substituindo-se os respectivos parâmetros nas equações (4.4.6) e (4.4.7), obtém-se a melhor alocação dos recursos entre os setores usuários, ou seja: $\mathrm{x}_{\mathrm{i}}^{* *}=6,43 \mathrm{ex}_{\mathrm{e}}^{*}=2,24$, ambos em m³ $/ \mathrm{s}$ De fato, essa alocação ótima da água internaliza os efeitos externos de cada setor usuário e maximiza o lucro agregado desses setores, p, o qual foi igual a $\mathrm{R} \$ 16.228 .513,09$, sendo que $\mathrm{R} \$ 16.108 .396,18$ foi resultante da agricultura irrigada e $\mathrm{R} \$ 120.116,91$ da geração de energia elétrica.

Os parâmetros utilizados nessa avaliação foram estimados com base nas informações levantadas ao longo deste texto e são: $\delta=0,164$, que capta o aumento de $16,4 \%$ no custo variável médio das culturas irrigadas na região ao expandir-se a área irrigada além dos 3.000 metros de distância das margens do manancial (faixa considerada de baixo custo de irrigação) ${ }^{12} ; \gamma_{i}=1,95 \times 10^{-4}\left[\right.$ ton $\left./ \mathrm{m}^{3}\right]$, o qual foi obtido tomando-se a área total a ser irrigada (10.700 ha) com as produtividades médias dos três cultivares mais produzidos na região (3,6 t/ha para o café, $7,2 \mathrm{t} /$ ha para o milho e $2,5 \mathrm{t} /$ ha para o feijão); $\gamma_{\mathrm{e}}=3,96 \times 10^{-4}\left[(\mathrm{MW} / \mathrm{h}) / \mathrm{m}^{3}\right]$, resultante do quociente da capacidade de geração total planejada para a barragem $(3,2 \mathrm{MW})$ em um intervalo de uma hora, pelo requerimento técnico de água nessa geração $\left(2,245 \mathrm{~m}^{3} / \mathrm{s}\right) ; \mathrm{P}_{\mathrm{i}}$ $=1.792,69[\mathrm{R} \$ /$ ton $]$, que é a média ponderada dos preços de mercado dos três cultivares, cujos pesos foram a proporção das áreas plantadas com cada cultura; $\mathrm{P}_{\mathrm{e}}^{*}=72,35[\mathrm{R} \$ /$ $(\mathrm{MW} / \mathrm{h})$ ], com base no Valor Normativo estabelecido para a tarifa de geração no país; $c_{i}=1.052,40[R \$ /$ ton], avaliado com base no percentual de $60 \%$ do preço médio de mercado do produtos agrícolas; $\mathrm{c}_{\mathrm{e}}=7,24[\mathrm{R} \$ /(\mathrm{MW} / \mathrm{h})]$, que foi estimado com base no custo marginal de curto prazo - correspondente a $10 \%$ do Valor Normativo da geração de energia elétrica no país; $\mathrm{p}_{\mathrm{i}}{ }^{*}=0,021\left[\mathrm{R} \$ / \mathrm{m}^{3}\right] ; \mathrm{p}_{\mathrm{e}}{ }^{*}=0,013[\mathrm{R} \$ /$ $\left.\mathrm{m}^{3}\right] ; \mathrm{x}_{\mathrm{i}}{ }^{\prime}=3\left[\mathrm{~m}^{3} / \mathrm{s}\right]$, definido pelo limite acima do qual os custos com a irrigação aumentam consideravelmente.

11 Admite-se que as condições de segunda ordem são satisfeitas.

12 Esse cálculo é fortemente influenciado pela cultura de café, a qual predomina na região em termos de área irrigada. 
A tabela 4.1 simula as principais variáveis nas vizinhanças do equilíbrio. Pode-se observar que os lucros agregados dos setores de ir rigação e geração de energia elétrica são maximizados quando a alocação é feita de tal forma a igualar-se os benefícios marginais líquidos desses dois setores. Em outras palavras, qualquer outra alocação dos recursos hídricos que não seja $\mathrm{x}_{\mathrm{i}}{ }^{*}=6,43 \mathrm{ex}_{\mathrm{e}}{ }^{*}=2,24$ é Pareto inferior, tendo em vista que os benefícios totais não são maximizados.

No entanto, para que a implementação da barragem de Cristalândia possa ser efetivamente justificada é necessária uma análise criteriosa de viabilidade desse projeto que, ao considerar os objetivos mais amplos da sociedade, mensure todos os benefícios e custos sociais. Essa análise será objeto das próximas seções. Vale lembrar que a avaliação social de projetos é um importante instrumento de gestão dos recursos hídricos, através do qual a sociedade otimiza a utilização de seus recursos escassos e norteia suas decisões de investimento. De fato, é através da avaliação social de projetos que o gerenciamento dos recursos hídricos pode orientar eficientemente os investimentos na economia de modo a obter o desenvolvimento regional integrado e sustentável, melhorando assim a qualidade de vida da sociedade como um todo.

TABELA 4.1: Simulações das principais variáveis nas vizinhas do equilíbrio

\begin{tabular}{ccccc}
\hline \multicolumn{2}{c}{ Vazão } & \multicolumn{3}{c}{ Lucro } \\
\hline $\begin{array}{c}\text { Irrigação } \\
\left(\mathbf{x}_{\mathbf{i}}\right)\end{array}$ & $\begin{array}{c}\text { Geração de EE } \\
\left(\mathbf{x}_{\mathbf{e}}\right)\end{array}$ & $\begin{array}{c}\text { Agregado } \\
(\pi)\end{array}$ & $\begin{array}{c}\text { Irrigação } \\
\left(\pi_{\mathbf{i}}\right)\end{array}$ & $\begin{array}{c}\text { Geração de EE } \\
\left(\pi_{\mathbf{e}}\right)\end{array}$ \\
\hline 4,50 & 4,17 & $14.909 .308,15$ & $14.011 .275,42$ & $898.032,73$ \\
5,00 & 3,67 & $15.504 .319,12$ & $14.807 .828,82$ & $696.490,30$ \\
5,50 & 3,17 & $15.922 .233,57$ & $15.427 .285,69$ & $494.947,87$ \\
6,00 & 2,67 & $16.163 .051,48$ & $15.869 .646,04$ & $293.405,44$ \\
$\mathbf{6 , 4 3}$ & $\mathbf{2 , 2 4}$ & $\mathbf{1 6 . 2 2 8 . 5 1 3 , 0 9}$ & $\mathbf{1 6 . 1 0 8 . 3 9 6 , 1 8}$ & $\mathbf{1 2 0 . 1 1 6 , 9 1}$ \\
6,50 & 2,17 & $16.226 .772,87$ & $16.134 .909,86$ & $91.863,01$ \\
7,00 & 1,67 & $16.113 .397,73$ & $16.223 .077,16$ & $-109.679,43$ \\
7,50 & 1,17 & $15.822 .926,07$ & $16.134 .147,92$ & $-311.221,86$ \\
\hline
\end{tabular}

Fonte: $\mathrm{O}$ autor

\section{AVALIAÇÃO DOS CUSTOS}

Esta seção avalia os custos sociais do projeto integrado de utilização múltipla dos recursos hídricos disponibilizados pela barragem de Cristalândia, tomando-se por base a melhor utilização desses recursos na região. Inicialmente, estimam-se os custos do projeto a preços de mercado, a partir dos quais corrigem-se as distorções para obter-se, finalmente, os custos sociais, que são os custos verdadeiramente incorridos pela sociedade.

\subsection{Custos a preço de mercado}

A tabela 5.1.1 contém a estimativa dos investimentos e dos custos de operação e manutenção do projeto de utilização múltipla dos recursos hídricos disponibilizados pela construção da barragem de Cristalândia, desagregada para duas diferentes vazões regularizadas com $100 \%$ de segurança $(1.400 \mathrm{l} / \mathrm{s}$ e $3.300 \mathrm{l} / \mathrm{s})$. Essa desagregação é importante porque permite apropriar a parcela do investimento com o barramento de menor vazão, que corresponde ao sistema de abastecimento de água das áreas urbana (de Brumado) e rural (para toda a população dispersa e a dessedentação de animais na área de influência do projeto), distinguindo-a daquela parcela imputada aos outros usos da água (ou seja, irrigação e geração de energia elétrica).

TABELA 5.1.1: Valor presente dos custos com o projeto de utilização múltipla dos recursos hídricos em cristalândia (r\$)

\begin{tabular}{lcc}
\hline & \multicolumn{2}{c}{ Vazão regularizada com 100\% de garantia } \\
\cline { 2 - 3 } Discriminação dos itens & $\mathbf{1 . 4 0 0}$ 1/s & $\mathbf{3 . 3 0 0}$ 1/s \\
\hline Barramento em concreto & 23.870 .804 & 40.866 .818 \\
$\quad$ Custo com capital & \multicolumn{3}{c}{} \\
Sistema de abastecimento urbano de Brumado & 12.413 .519 & \\
$\quad$ Custo com capital & 1.150 .177 & \\
$\quad$ Custo das linhas de distribuição de E.E. & 3.466 .014 & \\
$\quad$ Custo de operação (EE) e manutenção & 391.117 & \\
Sistemas de abastecimento rural dispersos & 39.823 & \\
$\quad$ Custo com capital & 158.619 & \\
$\quad$ Custo das linhas de distribuição de E.E. & - & 1.551 .410 \\
$\quad$ Custo de operação(EE) e manutenção & - & 851.450 \\
Sistemas simplificados de irrigação & - & \\
$\quad$ Custo com capital & - & 800.000 \\
$\quad$ Custo de operação (EE) e manutenção & - & 28.000 \\
Sistema de geração de energia elétrica (PCH) & &
\end{tabular}

\section{Fonte: $\mathrm{O}$ autor}

Tendo em vista que para atender os sistemas de abastecimento seria necessário construir um barramento de menor vazão, com menor dispêndio de capital, então nada mais justo que subtrair tal dispêndio do custo incorrido com a construção da barragem de maior vazão e imputá-lo ao abastecimento. Para imputar apropriadamente esse dispêndio de capital com os sistemas de abastecimento urbano e rural, rateou-se o montante em função da vazão demandada em cada um desses dois usos ${ }^{13}$. O diferencial de custo resultante será repartido entre os outros dois setores usuários, que são a agricultura irrigada e a geração de energia elétrica, de acordo com as proporções das vazões médias demandadas em cada uso ${ }^{14}$. A racionalidade para esse último rateio é que tanto os projetos de irrigação quanto a geração hidroelétrica se beneficiarão com a construção da barragem com maior vazão regularizada.

A tabela 5.1.2 mostra o valor presente e a anualidade dos custos com capital e operação e manutenção $(\mathrm{O} \& \mathrm{M})$

13 As proporções do consumo foram 96,7\% para o abastecimento urbano e 3,3\% para o rural e animal.

14 Cujos valores foram $62 \%$ para a irrigação e $38 \%$ para a geração de energia elétrica. 
TABELA 5.1.2: Valor presente e anualidade dos custos de capital e operação e manutenção dos sistemas de utilização da água

\begin{tabular}{lrrrr}
\hline \multirow{2}{*}{ Discriminação dos itens } & \multicolumn{2}{c}{ Valor presente dos custos } & \multicolumn{2}{c}{ Anualidade dos custos } \\
\cline { 2 - 5 } & \multicolumn{1}{c}{ Capital } & \multicolumn{1}{c}{ O \& M } & \multicolumn{1}{c}{ Capital } & \multicolumn{1}{c}{ O \& M } \\
\hline Abastecimento urbano & 31.936 .337 & 2.830 .884 & 4.863 .910 & 431.144 \\
Abastecimento rural e animal & 1.073 .063 & 129.553 & 163.428 & 19.731 \\
Irrigação & 10.573 .914 & 695.426 & 1.610 .409 & 105.913 \\
Geração de energia elétrica (PCH) & 6.307 .987 & 22.869 & 960.708 & 3.483 \\
Total & $\mathbf{4 9 . 8 9 1 . 3 0 1}$ & $\mathbf{3 . 6 7 8 . 7 3 2}$ & $\mathbf{7 . 5 9 8 . 4 5 5}$ & $\mathbf{5 6 0 . 2 7 2}$ \\
\hline
\end{tabular}

Fonte: $\mathrm{O}$ autor te os recursos sub avaliados pelo mercado ou subutilizem os recursos super avaliados pelo mesmo mercado. É, portanto, necessário introduzir mecanismos que corrijam as divergências entre os preços de mercado e os preços sociais, o que só é conseguido através da adoção de preços sociais. A tabela 5.2.1 contém um resumo das razões de preço social - RPS dos principais componentes de custos para conversão dos preços de mercado a preços sociais. dos sistemas de utilização múltipla dos recursos hídricos disponibilizados pela barragem de Cristalândia, com as correspondentes apropriações dos investimentos e levando-se em consideração tais ajustes.

\subsection{Preços sociais e} as razões de preços sociais

Tabela 5.2.1:

Razões entre os preços sociais e os preços de mercado

\begin{tabular}{|c|c|c|}
\hline \multirow{2}{*}{ Componente de custo } & \multicolumn{2}{|c|}{ RPS } \\
\hline & Valor mínimo & Valor máximo \\
\hline Capital & 1,25 & 1,50 \\
\hline Câmbio & 1,20 & 1,30 \\
\hline Trabalho especializado & $0,81 *$ & 1,00 \\
\hline Trabalho não especializado & $0,46^{*}$ & 0,60 \\
\hline Terra & \multicolumn{2}{|c|}{0,85} \\
\hline Energia elétrica (tarifa de fornecimento e suprimento) & 0,37 & 0,62 \\
\hline Óleo diesel & \multicolumn{2}{|c|}{0,73} \\
\hline Materiais nacionais e importados & $0,83 *$ & $0,88^{*}$ \\
\hline Equipamentos nacionais e importados & $0,80 *$ & $0,97 *$ \\
\hline
\end{tabular}

Fonte: Contador (1998) e Carrera-Fernandez \& Garrido (2002)

*Valores usualmente adotados pelo Banco Internacional para Reconstrução e Desenvolvimento - BIRD.

Em uma economia "ideal” - na qual os mercados operam livremente, em condições de concorrência perfeita, com pleno emprego e perfeita mobilidade dos recursos -, o preço de mercado seria um bom indicador do valor dos bens para a sociedade. No entanto, essas condições ideais são raramente verificadas na prática, devido a uma série de distorções, por exemplo, impostos, subsídios, regulamentações e externalidades tecnológicas. Desse modo, o sistema de preços de mercado passa a não ser um bom indicador dos custos para a sociedade, uma vez que esses preços contêm uma série de distorções em relação às condições ideais de equilíbrio. Nessas circunstâncias, a avaliação de projetos baseada em preços de mercado leva a economia a alocar os seus recursos ineficientemente, fazendo com que os agentes utilizem mais intensivamen-

\subsection{Custos sociais}

Objetivando avaliar os custos sociais do projeto de construção da barragem de Cristalândia, estimam-se a seguir as razões de preços sociais para cada um dos componentes de custo dos múltiplos sistemas de utilização dos recursos hídricos disponibilizados pela mesma. A tabela5.3.1 decompõe (em termos percentuais) os custos privados de capital e operação e manutenção, tomando-se por base os seus principais componentes, que são: mão-de-obra especializada e não especializada, materiais, insumos, equipamentos importados, óleo diesel, desapropriações e energia elétrica. A correspondente decomposição do custo social foi obtida multiplicando-se cada um dos componentes de custo privado pela sua respectiva razão de preço social - RPS. Finalmente, a RPS de cada sistema de utilização dos recursos hídricos é obtida somando-se as várias parcelas em cada coluna.

TABELA 5.3.1: Decomposição percentual dos custos privados e sociais dos principais componentes de custo dos sistemas de utilização da água

\begin{tabular}{|c|c|c|c|c|c|c|c|c|c|}
\hline \multirow{3}{*}{ Componentes } & \multicolumn{4}{|c|}{ Ótica privada } & \multirow{3}{*}{ RPS } & \multicolumn{4}{|c|}{ Ótica social } \\
\hline & \multicolumn{2}{|c|}{ Abastecimento } & \multirow{2}{*}{$\begin{array}{c}\text { Sistema } \\
\text { Irrigação }\end{array}$} & \multirow[t]{2}{*}{ GeraçãoE.E } & & \multicolumn{2}{|c|}{ Abastecimento } & \multirow{2}{*}{$\begin{array}{c}\text { Sistema } \\
\text { Irrigação }\end{array}$} & \multirow{2}{*}{ GeraçãoE.E } \\
\hline & urbano & rural & & & & urbano & rural & & \\
\hline \multicolumn{10}{|l|}{ Custos de capital } \\
\hline MDO especializada & 3,0 & 2,0 & 1,0 & 5,0 & 0,81 & 2,4 & 1,6 & 0,8 & 4,1 \\
\hline MDO não especializada & 5,0 & 6,0 & 5,0 & 5,0 & 0,46 & 2,3 & 2,8 & 2,3 & 2,3 \\
\hline Materiais & 73,0 & 75,0 & 78,0 & 70,0 & 0,83 & 60,6 & 62,3 & 64,7 & 58,1 \\
\hline Insumos & 12,0 & 13,0 & 15,0 & 15,0 & 0,80 & 9,6 & 10,4 & 12,0 & 12,0 \\
\hline Equipam. Importado & 3,0 & 1,5 & - & 3,0 & 1,20 & 3,6 & 1,8 & - & 3,6 \\
\hline Óleo diesel & 2,0 & 2,0 & 1,0 & 2,0 & 0,73 & 1,5 & 1,5 & 0,7 & 1,5 \\
\hline Desapropriações & 2,0 & 0,5 & - & - & 0,85 & 1,7 & 0,4 & - & - \\
\hline Total (\%) & 100,0 & 100,0 & 100,0 & 100,0 & - & 81,7 & 80,7 & 80,6 & 81,5 \\
\hline \multicolumn{10}{|l|}{ Custos de $\mathrm{O} \& \mathrm{M}$} \\
\hline MDO especializada & 2,0 & 1,0 & 1,0 & 30,0 & 0,81 & 1,6 & 0,8 & 0,8 & 24,3 \\
\hline MDO não especializada & 5,0 & 12,0 & 5,0 & 10,0 & 0,46 & 2,3 & 5,5 & 2,3 & 4,6 \\
\hline Materiais & 8,0 & 24,0 & 20,0 & 40,0 & 0,83 & 6,6 & 19,9 & 16,6 & 33,2 \\
\hline Insumos & 3,0 & 25,0 & 15,0 & 20,0 & 0,80 & 2,4 & 20,0 & 12,0 & 16,0 \\
\hline Energia elétrica & 82,0 & 38,0 & 59,0 & - & 0,37 & 30,3 & 14,1 & 21,8 & - \\
\hline Total (\%) & 100,0 & 100,0 & 100,0 & 100,0 & - & 43,3 & 60,3 & 53,5 & 78,1 \\
\hline
\end{tabular}

Fonte: tabela 5.2.1 e cálculos indicados no texto 
Tomando-se os custos privados para cada um dos sistemas de utilização dos recursos hídricos previstos na barragem de Cristalândia - mostrados na tabela 5.1.2 - e as RPS obtidas na tabela 5.3.1, podem-se então obter os respectivos custos sociais. A tabela 5.3.2 mostra o custo social para cada uma das modalidades de uso da água vislumbradas no projeto de construção da barragem de Cristalândia. os do sistema, ao utilizarem a água no consumo, como produto final, ou na produção, como insumo de produção. Assim, a cobrança pelo uso da água é também justificada como mecanismo de correção das distorções entre o custo social e o custo privado. Dessa forma, além de gerar os recursos necessários para financiar a atividade de gerenciamento dos recursos hídricos, a cobrança pelo uso da água funciona como instrumento para a internalização dos efeitos externos que cada usuário de um sistema hídrico

TABELA 5.3.2: Custo social dos sistemas de utilização dos recursos hídricos

\begin{tabular}{|c|c|c|c|c|c|c|}
\hline \multirow{2}{*}{ Discriminação dos itens } & \multicolumn{2}{|c|}{ Custo privado (R\$) } & \multicolumn{2}{|c|}{ RPS } & \multicolumn{2}{|c|}{ Custo social (R\$) } \\
\hline & Capital & $O \& M$ & Capital & $O \& M$ & Capital & O\& M \\
\hline \multicolumn{7}{|l|}{ Valor presente } \\
\hline Sistema de abastecimento de Brumado & 31.936 .337 & 2.830 .884 & 0,82 & 0,43 & 26.085 .600 & 1.225 .773 \\
\hline Sistemas dispersos de abastecimento & 1.073 .063 & 129.553 & 0,81 & 0,60 & 866.123 & 78.133 \\
\hline Sistemas simplificados de irrigação & 10.573 .914 & 695.426 & 0,81 & 0,54 & 8.520 .460 & 372.331 \\
\hline Geração de energia elétrica (PCH) & 6.307 .987 & 22.869 & 0,82 & 0,78 & 5.141 .640 & 17.861 \\
\hline Total & 49.891.301 & 3.678.732 & - & - & 40.613 .823 & 1.694 .098 \\
\hline \multicolumn{7}{|l|}{ Anualidade } \\
\hline Sistema de abastecimento de Brumado & 4.863 .910 & 431.144 & 0,82 & 0,43 & 3.972 .842 & 186.685 \\
\hline Sistemas dispersos de abastecimento & 163.428 & 19.731 & 0,81 & 0,60 & 131.911 & 11.900 \\
\hline Sistemas simplificados de irrigação & 1.610 .409 & 105.913 & 0,81 & 0,54 & 1.297 .668 & 56.706 \\
\hline Geração de energia elétrica (PCH) & 960.708 & 3.483 & 0,82 & 0,78 & 783.073 & 2.720 \\
\hline Total & 7.598.455 & 560.272 & - & - & 6.185 .493 & 258.011 \\
\hline
\end{tabular}

Fonte: tabelas 5.1.2 e 5.3.1 e cálculos no texto

\section{A COBRANÇA PELO USO DA ÁGUA}

Esta seção estima os preços pelo uso da água disponibilizada pela construção da barragem de Cristalândia, tomando-se por base as múltiplas demandas previstas pelos setores usuários desse recurso na região. Os preços avaliados servirão para quantificar os benefícios diretos, elemento fundamental no estudo de viabilidade social desse projeto.

A gestão dos recursos hídricos é uma atividade que se caracteriza, entre outros aspectos, por apresentar um custo marginal zero ou muito próximo de zero, principalmente no curto prazo, tendo em vista que a água é um recurso natural renovável e o aumento de sua disponibilidade não está, no curto prazo, diretamente associado a um incremento no custo com a expansão da sua oferta na bacia hidrográfica. Em outras palavras, a gestão dos recursos da água exige certos custos fixos, resultantes de investimentos, além, é claro, dos custos de operação e manutenção do próprio sistema hídrico. Isso significa que os usuários terão que, de alguma forma, arcar com esses custos, sob pena de a oferta de água ser reduzida ou até mesmo interrompida, com prejuízos para toda a sociedade. Nesse sentido, a cobrança pelo uso da água se justifica como mecanismo de financiamento dos investimentos e custos de operação e manutenção, imprescindíveis à atividade de gestão dos recursos hídricos.

A cobrança pelo uso da água é, também, justificada como forma de corrigir as externalidades negativas que os usuários dos recursos hídricos impõem aos demais usuári- impõe aos demais na sua decisão particular de utilizar água.

Um dos objetivos mais importantes da cobrança pelo uso da água é, portanto, garantir aos usuários dos recurcurso. Nesse sentido, a cobrança pelo uso da água funciona como um elemento educativo, que combate eficazmente o desperdício e garante um padrão aceitável de preservação desse recurso natural. A experiência internacional tem mostrado que a cobrança pelo uso da água, além de ser utilizada como forma de racionalizar o uso dos recursos hídricos, atua também como mecanismo eficiente de: gerenciar a demanda, aumentando a produtividade e a eficiência na utilização dos recursos hídricos; redistribuir os custos sociais de for ma mais eqüitativa; disciplinar a localização dos usuários, buscando a conservação dos recursos hídricos; e promover o desenvolvimento regional integrado, principalmente nas suas dimensões sociais e ambientais.

A despeito de se tratar de um instrumento relativamente novo no contexto da gestão dos recursos hídricos, o debate sobre a cobrança pelo uso da água no Brasil, que se iniciou na década de 80 , tem gerado uma quantidade razoavelmente grande de trabalhos e uma diversidade de metodologias no concernente aos mecanismos de formação de preços pelo uso dos recursos hídricos. No entanto, tendo em vista as várias metodologias propostas apresentam vantagens e desvantagens, ainda não há um consenso sobre o referencial metodológico a ser utilizado para nortear a formação de preços pelo uso da água no Brasil.

A valorização econômica da água e a implementação do instrumento de cobrança pelo uso em sistemas de bacias hidrográficas são temas bastante complexos que, além das questões econômicas, envolvem também questões legais, institucionais, ambientais, técnicas, e sociais. A escolha da metodologia mais apropriada para estabelecer um valor para a água é uma das tarefas mais difíceis pois, além de requerer um amplo conhecimento das várias teorias e modelos econômicos disponíveis, é necessário também conhecer as vantagens e desvantagens das mesmas. sos hídricos um uso eficiente desse re- 
Uma incursão na literatura econômica permite observar que existe uma ampla diversidade de metodologias para formação dos preços pelo uso de um bem público, como a água. Uma análise completa dessas metodologias alternativas de cobrança pelo uso da água pode ser encontrada em Carrera-Fernandez \& Garrido (2000). Deve-se ressaltar que essas metodologias se fundamentam em uma gama de diferentes teorias econômicas, mas todas elas buscam ou priorizam algum dos três princípios econômicos básicos, ou seja: (i) eficiência econômica com os recursos hídricos disponíveis; (ii) eficiência distributiva ou equidade na alocação dos recursos da água entre seus múltiplos usuários; e (iii) recuperação dos custos (autosustentabilidade financeira) no gerenciamento desses recursos.

A metodologia utilizada para nortear a determinação dos preços pelo uso da água será a do custo marginal social de longo prazo ou incremental social cost. Vale lembrar que o custo marginal social de longo prazo é o custo que a sociedade terá que incorrer para expandir a oferta de água em um metro cúbico a mais desse recurso. Esse custo deverá incluir a renda (ou quase-renda) econômica atribuída à escassez da água, a qual é justificada como forma de garantir os recursos necessários para recuperar (total ou parcialmente) os investimentos realizados, assegurar os futuros investimentos necessários ao sistema hídrico, permitir a manutenção e operação do próprio sistema e internalizar aos custos privados os efeitos externos.

Segundo os defensores dessa política de preço, entre eles o Banco Internacional para Reconstrução e Desenvolvimento - BIRD e o Banco Interamericano de Desenvolvimento $\mathrm{BID}$, preço igual ao custo marginal social de longo prazo sinaliza para a sociedade a necessidade de investimentos futuros, indispensáveis para suprir o crescimento de demanda, além de: (i) estimular o comportamento racional da demanda, através do aumento da produtividade e da eficiência de uso dos recursos hídricos; (ii) evitar oscilações de preço de um ano para outro, que se verificaria ao se adotar o custo marginal de curto prazo; e (iii) permitir a geração de recursos programados para financiar os investimentos planejados necessários para garantir o aumento de oferta dos recursos hídricos, vez que esse conceito também considera os custos futuros.

Tendo em vista que a múltipla utilização dos recursos hídricos disponibilizados pela barragem de Cristalândia envolverá diferentes custos de oportunidade da água, os quais dependerão do uso que se dê à água, o custo marginal social de produção de água bruta no longo prazo também terá que ser diferenciado por finalidades de uso. Assim, o custo marginal social de longo prazo incorrido ao se expandir a oferta de água para o setor usuário da água j poderá ser avaliado da seguinte forma:

$$
\mathrm{CMg}_{j}{ }^{\mathrm{LP}}=\left[\sum_{\mathrm{t}=0}^{\mathrm{T}}\left[\mathrm{I}_{\mathrm{j}}(\mathrm{t})+\mathrm{C}_{\mathrm{t}}(\mathrm{t})\right] /(1+\rho)^{\mathrm{t}}\right] /\left[\sum_{\mathrm{t}=0}^{\mathrm{T}} \mathrm{x}_{\mathrm{j}}(\mathrm{t}) /(1+\rho)^{\mathrm{t}}\right]
$$

sendo que $\mathrm{I}_{\mathrm{j}}(\mathrm{t})$ é a parcela da amortização do investimento do projeto, a preços sociais, exigido pelo setor usuário j no ano t, $C_{i}(t)$ são os custos sociais de operação e manutenção necessários para disponibilizar os recursos hídricos para o setor usuário $\mathrm{j}$ no tempo $t, \mathrm{x}_{\mathrm{i}}(\mathrm{t})$ é a captação incremental de água bruta demandada pelo uso $\mathrm{j}$ no ano $\mathrm{t}, \mathrm{r}$ é o custo de oportunidade do capital (ou taxa social de desconto) e T é o horizonte de planejamento. Ressalte-se que o numerador dessa expressão representa o valor presente dos custos sociais de capital e de operação e manutenção ao longo da vida útil do projeto, enquanto que o denominador representa o valor presente dos recursos hídricos disponibilizados pelo projeto ao longo da vida útil do mesmo.

A tabela 6.1 mostra o valor presente do incremento de oferta de água propiciado pela construção da barragem de Cristalândia em cada um dos usos múltiplos previstos no projeto. Vale ressaltar que o acréscimo dos recursos hídricos disponibilizados pela barragem foi dimensionado de acordo com a melhor alocação desses recursos, observando-se a evolução das múltiplas demandas por água na região de influência do projeto.

\begin{tabular}{|c|c|c|c|c|c|c|}
\hline Modalidade de uso & VP da água & 2002 & 2007 & 2012 & 2022 & 2032 \\
\hline Abastecimento urbano & 30.233 & 4.028 & 4.457 & 4.932 & 6.039 & 7.394 \\
\hline Abastecimento rural e animal & 1.068 & 159 & 162 & 165 & 171 & 177 \\
\hline Irrigação & 420.822 & 4.024 & 53.678 & 103.331 & 202.638 & 202.638 \\
\hline Geração de energia elétrica & 397.593 & 55.073 & 60.854 & 67.241 & 57.952 & 70.798 \\
\hline Total & 849.716 & 63.284 & 119.151 & 175.669 & 266.800 & 281.007 \\
\hline
\end{tabular}

A tabela 6.2 mostra os preços sociais pelo uso da água bruta disponibilizada pelo projeto de construção da barragem de Cristalândia, para cada um dos usos múltiplos, com base no custo marginal social de longo prazo. Deve-se ressaltar que tais preços foram obtidos dividindo-se o valor presente dos custos sociais (tabela 5.3.2) pelo valor presente da água disponibilizada pela referida barragem (tabela 6.1) em cada modalidade de uso.

TABELA 6.2: Preços sociais pelo uso $\mathrm{da}$ água bruta por modalidade de uso

\begin{tabular}{lc}
\hline Modalidade de uso & Preço social $\left(\mathbf{R} \$ \mathbf{m} \mathbf{m}^{\mathbf{3}}\right)$ \\
\hline Abastecimento urbano & 0,903 \\
Abastecimento rural e animal & 0,884 \\
Irrigação & 0,021 \\
Geração de energia elétrica $(\mathrm{PCH})$ & 0,013 \\
\hline
\end{tabular}

Fonte: $\mathrm{O}$ autor 


\section{AVALIAÇÃO DOS BENEFÍCIOS}

Quando analisado sob o ponto de vista social, o projeto pode apresentar benefícios diretos e indiretos. Os benefícios diretos são aqueles que resultam da cobrança pelo uso da água bruta disponibilizada pelo projeto, com base em preços que espelhem o custo marginal social, bem como pela receita gerada com a energia elétrica produzida no barramento. Os benefícios indiretos são aqueles que afetam positivamente a sociedade, através de reduções de doenças infecto-contagiosas e melhoria no nível de vida da população atendida, os quais não são contabilizados pelo mecanismo de mercado, mas que não existiriam sem a implementação desse projeto.

A tabela 7.1 mostra o valor presente e a anualidade do benefício social direto, por modalidade de uso, resultante da cobrança pelo uso dos recursos hídricos disponibilizados pela barragem de Cristalândia e da comercialização da energia gerada na PCH, tomando-se por base os preços sociais. Esse benefício social foi obtido ao multiplicar-se os preços sociais (da água em cada uso e da energia) pela respectiva quantidade (água disponibilizada e energia gerada). Deve-se ressaltar que o preço social da energia foi obtido multiplicando-se a RPS da mesma pelas seguintes tarifas de mercado: (i) $\mathrm{R} \$ 0,1807$ porkWh para consumo na ponta; (ii) $\mathrm{R} \$ 0,084$ por $\mathrm{kWh}$ para consumo fora da ponta; (iii) $\mathrm{R} \$ 28,59$ por $\mathrm{kWh}$ para garantia de demanda na ponta; e (iv) $\mathrm{R} \$ 9,51$ por $\mathrm{kWh}$ para garantia de demanda fora da ponta.

TABELA 7.1: Benefício social direto

\begin{tabular}{lrr}
\hline Modalidade de uso & Valor presente & Anualidade \\
\hline Cobrança pelo uso da água & & \\
$\quad$ Abastecimento urbano & 27.311 .373 & 4.159 .528 \\
Abastecimento rural e animal & 944.256 & 143.810 \\
Irrigação & 8.892 .791 & 1.354 .374 \\
Geração de energia elétrica & 5.159 .501 & 785.793 \\
Venda da energia elétrica gerada na PCH & 1.129 .066 & 171.957 \\
Total & $\mathbf{4 3 . 4 3 6 . 9 8 7}$ & $\mathbf{6 . 6 1 5 . 4 6 2}$ \\
\hline
\end{tabular}

Fonte: $\mathrm{O}$ autor

Além desses benefícios diretos propiciados pelo aumento da disponibilidade de água bruta para suprir os sistemas abastecimento público (urbano e rural), o projeto também apresenta benefícios indiretos resultantes da redução de episódios de doenças infecto-contagiosas, que são apropriados pela sociedade através de custos evitáveis com internação hospitalar, procedimentos médicos e medicamentos.

Uma forma de avaliar parte desses benefícios indiretos pode ser feita tomando-se por base a incidência de ca- sos de diarréia. De fato, a diarréia é a principal doença efetivamente redutível por melhoria e expansão de sistemas de abastecimento de água potável. Este fato foi comprovado pelo Consórcio GEOHIDRO-ECODIT através de pesquisa direta em 60 municípios baianos (CarreraFerandez \& Gar rido, 2002). Além disso, a indisponibilidade de informações razoavelmente confiáveis para as demais doenças redutíveis por expansão no abastecimento de água reforça ainda mais a hipótese de utilização das informações relacionadas apenas à diarréia. $\mathrm{O}$ ponto de partida para mensurar os benefícios com a redução de casos de diarréia é reconhecer que existe uma relação (linear) entre o percentual dos domicílios ligados a um sistema de abastecimento de água e a taxa de prevalência de diarréia, a qual é especificada por:

$$
I_{D}=5,18-0,0256 R
$$

onde $\mathrm{I}_{\mathrm{D}}$ é a incidência de diarréia no período de uma semana e $\mathrm{R}$ é o percentul de domicílios ligados ao sistema de abastecimento de água.

Aplicando-se a expressão (7.1), pode-se obter a redução dos casos de diarréia no caso do abastecimento de água de Brumado, cujo município tem um percentual de $95,4 \%$ de domicílios ligados à rede de abastecimento. Nesse caso, haverá uma redução semanal de $0,12 \%$ nos casos de diarréia, o que representa uma redução anual de 6,14\%. Para as outras localidades rurais (Cristalândia, faixa da adutora e pequenos povoados), cuja população não conta com rede de abastecimento de água, a redução semanal dos casos de diarréia seria de 5,18\% (ou $133,49 \%$ ao ano). A tabela 7.2 mostra as populações beneficiadas e a redução anual de casos de diarréia propiciada pela expansão dos recursos hídricos disponibilizados pela construção da barragem de Cristalândia ao longo do horizonte do projeto. A redução do número de casos de diarréia foi obtida aplicando-se esses percentuais às populações beneficiadas pelo projeto.
TABELA 7.2: Populações beneficiadas e redução de casos de diarréia propiciada pela água disponibilizada pela barragem de cristalândia

\begin{tabular}{|c|c|c|c|c|c|}
\hline Localidade & 2002 & 2007 & 2012 & 2022 & 2032 \\
\hline \multicolumn{6}{|l|}{ População beneficiada } \\
\hline Brumado & 51.094 & 56.536 & 62.559 & 76.596 & 93.783 \\
\hline Faixa do rio e da adutora & 821 & 841 & 862 & 906 & 953 \\
\hline Pequenos povoados rurais & 1.596 & 1.636 & 1.678 & 1.763 & 1.854 \\
\hline Total & 53.511 & 59.013 & 65.099 & 79.265 & 96.590 \\
\hline \multicolumn{6}{|c|}{ Redução anual de casos de diarréia } \\
\hline Brumado & 3.137 & 3.472 & 3.841 & 4.703 & 5.759 \\
\hline Faixa do rio e da adutora & 1.096 & 1.123 & 1.151 & 1.209 & 1.272 \\
\hline Pequenos povoados rurais & 2.130 & 2.184 & 2.240 & 2.353 & 2.475 \\
\hline Total & 6.363 & 6.779 & 7.232 & 8.265 & 9.506 \\
\hline
\end{tabular}

Fonte: $\mathrm{O}$ autor 
O custo médio de um episódio de diarréia (em termos de internação hospitalar, procedimentos médicos e medicamentos) foi estimado pela GEOHIDRO-ECODIT e se situa em torno de US $\$ 13,50$. Tomando-se a taxa de câmbio de 3,50 do Real em relação ao Dólar, tem-se um custo evitável de $R \$ 47,25$. O benefício indireto anual decorrente da expansão da oferta dos recursos hídricos pelo projeto será igual à redução anual esperada de casos de diarréia multiplicada por esse valor, o qual deverá fluir durante todo o horizonte de análise do projeto. A tabela 7.3 mostra o benefício indireto da redução de casos de diarréia resultante dos recursos hídricos disponibilizados pela barragem de Cristalândia para os sistemas de abastecimento de água.

TABELA 7.3: Benefício indireto resultante da redução de casos de diarréia propiciado pela água de cristalândia para o abstecimento público

\begin{tabular}{lrrrrr}
\hline Localidade & 2002 & $\mathbf{2 0 0 7}$ & $\mathbf{2 0 1 2}$ & $\mathbf{2 0 2 2}$ & \multicolumn{1}{c}{$\mathbf{2 0 3 2}$} \\
\hline Abastecimento urbano & & & & & \\
Brumado & 148.240 & 164.029 & 181.503 & 222.229 & 272.094 \\
Abastecimento rural disperso & & & & & \\
Faixa do rio e da adutora & 51.782 & 53.044 & 54.368 & 57.143 & 60.108 \\
Pequenos povoados rurais & 100.663 & 103.186 & 105.835 & 111.196 & 116.935 \\
Total & $\mathbf{3 0 0 . 6 8 5}$ & $\mathbf{3 2 0 . 2 5 9}$ & $\mathbf{3 4 1 . 7 0 6}$ & $\mathbf{3 9 0 . 5 6 8}$ & $\mathbf{4 4 9 . 1 3 7}$ \\
\hline
\end{tabular}

Fonte: $\mathrm{O}$ autor nado projeto deve ou não ser implementado ou escolher o melhor entre vários projetos alternativos.

Deve-se ressaltar que a análise de viabilidade social de projetos difere da análise de viabilidade econômica não somente pela ótica dos objetivos, mas também pela forma como os benefícios e custos desses projetos são avaliados. Quanto ao primeiro ponto de divergência, é obvio que as decisões de investimento público não consideram os mesmos objetiv

No que concerne ao segundo ponto de divergência, a técnica de avaliação social examina todos os efeitos diretos e indiretos causados pelo projeto, além de avaliar a repercussão dos recursos utilizados pelo mesmo sobre os custos efetivamente incorridos pela sociedade. Por outro lado, a análise de viabilidade de projetos sob o ponto de vista privado examina apenas os benefícios e os custos diretos desse projeto passíveis de serem contabilizados pelo mecanismo de mercado. $\mathrm{Na}$ avaliação social de projetos, todos os efeitos externos tecnológicos do projeto devem ser identificados e incorporados à análise ${ }^{15}$. Essa internalização dos efeitos externos é, de fato, uma característica importante que diferencia a análise social da análise privada de projetos.

Após terem sido quantificados os custos e benefícios sociais diretos e indiretos do projeto em análise, faz-se necessário confrontar os benefícios totais com os custos totais que a sociedade terá de arcar para prover tal projeto. A decisão de implementar um projeto individual ou escolher o melhor projeto entre projetos alternativos deve ser necessariamente baseada em função de critérios de viabilidade econômica. Os três indicadores econômicos mais utilizados para seleção de projetos são: (i) valor presente líquido (VPL); (ii) relação benefício-custo (B/C); e (iii) taxa interna de retorno (TIR).

O VPL é o valor presente da diferença entre o fluxo de benefícios e custos, descontado a uma taxa apropriada, ou seja, que reflita o verdadeiro custo de oportunidade do capital para a sociedade:

$$
\mathrm{VPL}=\sum_{\mathrm{t}=0}^{\mathrm{T}}\left(\mathrm{B}_{\mathrm{t}}-\mathrm{C}_{\mathrm{t}}\right) /(1+\rho)^{\mathrm{t}}
$$
tos. Assim, o objetivo primordial da análise de viabilidade econômica de investimentos é estabelecer se um determi-

15 Os efeitos indiretos (ou efeitos externos) podem ser classificados em tecnológicos e pecuniários. Os efeitos externos tecnológicos são aqueles que envolvem alterações reais na economia e representam mudanças de bem-estar social e, portanto, devem ser contabilizados na análise. Por outro lado, os efeitos externos pecuniários, também denominados de efeitos econômicos secundários ou indiretos, são aqueles que refletem mudanças de preços e rendas em outros setores da economia, causadas por deslocamentos de oferta ou demanda, e representam, em geral, mudanças na distribuição de renda em vez de impactos na alocação dos recursos. A inclusão dos efeitos externos pecuniários na análise de custos e benefícios seria incorreta, pois representaria dupla contagem. 
onde $\mathrm{B}_{\mathrm{t}}$ é o benefício social total do projeto no tempo t; $C_{t}$ é o custo social total no período $t$, que deve incluir despesas com capital, operação e manutenção ${ }^{1}$; é a taxa social de desconto (ou custo social do capital); e T é o horizonte do projeto. O VPL é um critério rigoroso e isento de falhas técnicas. Segundo esse critério, um projeto é economicamente viável se o VPL for positivo. Por outro lado, o projeto é considerado economicamente inviável se o VPL for negativo. Quando decidindo entre projetos alternativos, quanto maior for o VPL, tanto melhor será o projeto.

A relação benefício/custo é definida pelo quociente entre o valor presente dos benefícios sociais e o valor presente dos custos sociais, ambos descontados à taxa $r$ (custo social do capital):

$$
\left.\mathrm{B} / \mathrm{C}=\left[\sum_{\mathrm{t}=0}^{\mathrm{T}} \mathrm{B}_{\mathrm{t}} /(1+\rho)^{\mathrm{t}}\right] / \underset{\mathrm{t}=0}{\mathrm{~T}} \mathrm{C}_{\mathrm{t}} /(1+\rho)^{\mathrm{t}}\right]
$$

De acordo com esse critério, um projeto é economicamente viável se a relação $\mathrm{B} / \mathrm{C}$ for maior que a unidade, $\mathrm{e}$ inviável quando a relação $\mathrm{B} / \mathrm{C}$ for menor que um. No caso de projetos alternativos, quanto maior a relação $\mathrm{B} / \mathrm{C}$, tanto melhor será o projeto. Vale a pena ressaltar que um projeto que apresenta VPL positivo implica necessariamente uma relação $\mathrm{B} / \mathrm{C}$ maior que a unidade, e vice-versa.

A TIR é a taxa de desconto, $t$, que torna o VPL de um projeto igual a zero:

$$
\sum_{t=0}^{T}\left(B_{t}-C_{t}\right) /(1+\tau)^{t}=0
$$

Segundo esse critério, quanto maior for a TIR melhor será o projeto. No entanto, a análise social de projetos exige que a TIR seja comparada com o custo social do capital. Especificamente, se $\tau>\rho$, então o projeto é economicamente viável; enquanto que este é considerado inviável se $\tau<\rho$.

A tabela 8.1 contém os indicadores de viabilidade social do projeto de utilização conjunta dos recursos hídricos disponibilizados pela construção da barragem de Cristalândia. Uma análise desse quadro permite constatar que o projeto é viável sob o ponto de vista social, o que é garantido por todos os indicadores de viabilidade desse projeto. De fato, o valor presente líquido (VPL) foi positivo e atingiu a expressiva cifra de $\mathrm{R} \$ 2.847 .185,00$; a relação benefício/custo foi maior que a unidade, sendo que os benefí- cios excedem os custos em $8 \%$; e a taxa interna de retorno do projeto, que foi de $16,0 \%$, foi significativamente superior à taxa social de desconto de $15 \%$.

TABELA 8.1: Indicadores de viabilidade social do Projeto de utilização conjunta dos recursos hídricos

\begin{tabular}{lr}
\hline Indicadores de viabilidade & \multicolumn{1}{c}{ Valor } \\
\hline VPL & 2.847 .185 \\
B/C & 1,08 \\
TIR & $16,0 \%$ \\
\hline
\end{tabular}

\section{Fonte: $\mathrm{O}$ autor}

Portanto, constata-se que o projeto de utilização conjunta dos recursos hídricos disponibilizados pela barragem de Cristalândia é viável sob o ponto de vista mais amplo da sociedade, podendo ser implementado. Esse fato, de certa forma, já era esperado tendo em vista que a disponibilidade de água bruta é um bem que apresenta a característica de gerar um fluxo de benefícios maior do que aquele apropriado diretamente por seus usuários. Para que esses benefícios continuem fluindo, é necessário estabelecer uma gestão integrada e auto-sustentável financeiramente, que cobre efetivamente dos múltiplos usuários dos recursos hídricos os custos verdadeiramente incorridos pela sociedade.

\section{CONCLUSÃO}

Este artigo abordou a questão da busca pela melhor utilização conjunta dos recursos hídricos em uma perspectiva regional integrada, tema da maior importância para o desenvolvimento econômico sustentável. Este ensaio destacou que, além dos instrumentos tradicionais de ação e controle inerentes ao poder público, os instrumentos econômicos de alocação dos recursos hídricos entre seus múltiplos usuários, entre eles a cobrança pelo uso da água e a avaliação social de projetos, são elementos fundamentais para a tarefa de gestão e planejamento desses recursos. A análise desenvolvida ao longo deste ensaio tomou como ponto de partida o reconhecimento de que a água é um bem econômico de grande valor de uso, além do que os usuários múltiplos têm, preliminarmente, iguais condições de acesso aos recursos da água. Em um segundo momento, entretanto, a análise se inclina para indicar que essa igualdade de condição precisa ceder lugar a que o uso que comandar o maior benefício social líquido deva preponderar sobre os demais, afigurando-se como o uso prioritário das águas do sistema hídrico.

16 É importante ressaltar que ao serem incluídos os custos de capital (investimentos do projeto) não se deve apropriar a depreciação do capital, assim como não devem ser incluídos os custos financeiros (despesas de juros), uma vez que a taxa social de desconto utilizada na avaliação já reflete tais parcelas. 
Oprojeto multifuncional de Cristalândia contribui para o desenvolvimento integrado e sustentável dessa região, na medida em que harmoniza os interesses dos diversos setores usuários da água envolvidos, legando para as futuras gerações a necessária base de recursos hídricos, além de buscar uma maior eficiência no gerenciamento e uma maior integração no planejamento desses recursos. A avaliação social criteriosa a que foi submetido o projeto de Cristalândia comprovou a importância da construção dessa barragem para a região, fato esse garantido por todos os indicadores de viabilidade econômica apresentados pelo projeto. Além do mais, o projeto estabelece um modelo de gestão intersetorial simétrico e harmonioso, voltado, sobretudo, para atender o importante princípio dos usos múltiplos dos recursos hídricos, além do que busca a autosustentabilidade financeira do gerenciamento dos recursos hídricos, importante elemento na nova política nacional dos recursos hídricos.

Este estudo permitiu concluir que a utilização dos recursos hídricos pelos setores de abastecimento público e irrigação comanda um valor econômico para a sociedade bem maior que o valor propiciado pela geração de energia elétrica. Isso significa que, sob o prisma do princípio dos usos múltiplos, políticas que priorizam a utilização dos recursos hídricos para o abastecimento de água potável e para a agricultura irrigada, ao invés da geração de energia elétrica, são Pareto superior e, portanto, estariam contribuindo para levar a economia na direção da fronteira Pareto ótimo, com ganhos líquidos para toda a sociedade. No entanto, a política de utilização prioritária dos recursos hídricos para o abastecimento público e para a irrigação não significa absolutamente que se deva descartar a sua utilização para geração de energia elétrica. De fato, o abastecimento público e o desenvolvimento da agricultura irrigada, nessa região, não poderão prescindir desses aproveitamentos hidrelétricos.
Espera-se que este estudo possa servir para subsidiar as políticas públicas de investimentos na área de recursos hídricos, no sentido de que estas busquem uma maior integração no planejamento desses recursos e sejam voltadas para uma perspectiva regional mais ampla. Além do mais, espera-se que esta análise possa também contribuir para aprimorar o gerenciamento dos recursos hídricos no país, na medida em que orienta as ações públicas e privadas de forma a melhorar a alocação e a utilização desses recursos na economia, permitindo que sejam obtidos os maiores benefícios sociais e garantindo o desenvolvimento sustentável dessas regiões.

\section{REFERÊNCIAS BIBLIOGRÁFICAS}

CARRERA-FERNANDEZ, José; GARRIDO, Raymundo-José. Teorias e metodologias de cobrança pelo uso da água em bacias hidrográficas. Economia, v.2, n.2. Campinas, 2000.

CARRERA-FERNANDEZ, José; GARRIDO, Raymundo-José. Economia dos recursos bidricos. Salvador: EDUFBA, 2002.

CARRERA-FERNANDEZ, José; FERREIRA, Paulo Moraes. Otimização dos recursos hídricos em sistemas de bacia hidrográfica: o caso da bacia do rio Formoso, na Bahia. Revista Econômica do Nordeste, v. 33, n. 3, p. 536-553. Fortaleza, 2002.

CONTADOR, Cláudio Roberto. Projetos sociais. São Paulo: Atlas, 1998.

MAS-COLELL, Andreu; WHINSTON, M. D.; GREEN, J. R. Microeconomic Theory. New York: Oxford University Press, 1995.

ROSEGRANT, M. W.; RINGLER, C.; MCKINNEY, D. C.; CAI, X.; KELLER A.; DONOSO G. Integrated Economichydrologic water modeling at the basin scale: the Maipo river basin. Environment and Production Technology Division - EPTD Discussion Paper n. 63. International Food Policy research Institute. New York: June, 2000. 
A gestão e o planejamento integrado dos recursos hídricos: o caso da barragem de cristalândia, na Bahia. 